\title{
L'évêque Scollard et la question canadienne-française. Le diocèse de Sault-Sainte-Marie au coeur du conflit franco-irlandais (1904-1934)
}

\section{Michel Bock}

Volume 10, 2014

URI : https://id.erudit.org/iderudit/1039290ar

DOI : https://doi.org/10.7202/1039290ar

Aller au sommaire du numéro

Éditeur(s)

Société Charlevoix

Presses de l’Université d’Ottawa

ISSN

1203-4371 (imprimé)

2371-6878 (numérique)

Découvrir la revue

Citer cet article

Bock, M. (2014). L'évêque Scollard et la question canadienne-française. Le diocèse de Sault-Sainte-Marie au coeur du conflit franco-irlandais (1904-1934). Cahiers Charlevoix, 10, 13-63. https://doi.org/10.7202/1039290ar
Résumé de l'article

Michel Bock porte son regard sur le conflit franco-irlandais qui a divisé les catholiques du diocèse de Sault-Sainte-Marie, dans le nord de l'Ontario, pendant le règne de l'évêque David Scollard (1904-1934). En situant le conflit dans le contexte des événements qui déclenchèrent la crise du Règlement 17 (1912-1927) et dans celui de la Première Guerre mondiale (1914-1918), il analyse le rôle qu'ont pu jouer les nombreux affrontements entre coreligionnaires canadiens-français et irlando-canadiens entourant les nominations paroissiales et le bilinguisme scolaire dans la mutation du champ intellectuel franco-ontarien. En effet, la double intervention du Saint-Siège dans la crise des écoles bilingues, par les encycliques Commisso Divinitus (1916) et Litteris Apostolicis (1918), conduisit l'élite nationaliste de l'Ontario français non seulement à abandonner l'ardeur belliqueuse et l'intransigeance qui caractérisaient son combat contre les « Irlandais » depuis le début du siècle, mais aussi à remettre en cause, du moins publiquement, le fondement même du nationalisme canadien-français traditionaliste, soit l'union, jugée inviolable jusqu'alors, des questions nationale et religieuse. La thèse de la langue "gardienne " de la foi étant devenue insoutenable aux yeux de la hiérarchie romaine, dont la compréhension du nationalisme était pour l'essentiel inspirée du contexte européen, l'élite franco-ontarienne sentit la nécessité de faire preuve d'une plus grande modération idéologique et stratégique dans ses tractations avec l'évêque Scollard. 


\title{
L'évêque Scollard et la question canadienne-française. Le diocèse de Sault-Sainte-Marie au cour du conflit franco-irlandais (1904-1934)
}

\author{
Michel Bock \\ Chaire de recherche sur l'histoire \\ de la francophonie canadienne \\ Université d'Ottawa
}




\section{SOMMAIRE}

I - JAUGER L'ADVERSAIRE

A. Un difficile début de règne

(1904-1907)

B. La fondation de la paroisse

Saint-Vincent-de-Paul de North-Bay

(1907-1914)

II - L'EXACERBATION DES INIMITIÉS

A. La campagne pour déloger Scollard

(1908 et 1913)

B. L'affaire de Sudbury (1915-1920)

III - L'AFFAIRE DU DROIT

A. Le déclenchement de la crise (1919)

B. Accalmie ou guerre froide ?

Le dénouement de la crise et ses suites (1920-1934) 


\section{L'évêque Scollard et la question canadienne-française. Le diocèse de Sault-Sainte-Marie au cour du conflit franco-irlandais (1904-1934)}

En 1908, Napoléon Lepage, de Blezard-Valley, petite communauté agricole située près de Sudbury, tenta d'obtenir du délégué apostolique au Canada, Donato Sbarretti, une dispense qui lui eût permis d'épouser l'une de ses proches parentes. Lepage avait d'abord présenté sa demande à l'évêque de Sault-Sainte-Marie, David Joseph Scollard, qui s'y était opposé catégoriquement ${ }^{1}$. Interrogé par le délégué apostolique sur le contexte entourant cette requête, Scollard justifia de la manière suivante sa décision d'interdire les mariages entre personnes «closely related by blood» : «The physical results in the children of parents closely related are most deplorable, especially among the French Canadian habitants of the diocese who, at best, are rather ignorant, and whose minds are not very bright. I have seen so many physically deformed, that I came to the conclusion to reduce the number of these marriages to the lowest possible minimum $[\ldots]^{2}$. » Sbarretti se rangea derrière Scollard, ne voyant rien qui pût justifier le renversement d'une décision prise par le chef de l'Église diocésaine ${ }^{3}$. Il est pour le moins difficile de dénombrer avec exactitude les cas d'infirmités et de malformations génétiques résultant d'unions consanguines qui avaient pu s'abattre, à l'époque, sur la population canadienne-

1. Lettre de Napoléon Lepage à Donato Sbarretti, 20 juin 1908, Archives secrètes du Vatican à Rome (dorénavant Asv), Archives de la nonciature du Canada (dorénavant ANC), 66.13.

2. Lettre de David Scollard à Donato Sbarretti, 3 juillet 1908, Asv, ANC, 66.13.

3. Lettre de Donato Sbarretti à Napoléon Lepage, 5 juillet 1908, Asv, Anc, 66.13 . 
française du diocèse de Sault-Sainte-Marie. Les impressions fournies par Scollard à Sbarretti, qui semblaient faire état d'une véritable horde d'estropiés parmi les Franco-Ontariens, avaient de quoi surprendre et inquiéter, toutefois...

L'anecdote frôle le burlesque, mais elle n'en donne pas moins un bon aperçu des dispositions que pouvait avoir le prélat envers ses ouailles canadiennes-françaises, qu'il ne semblait pas tenir en très haute estime, c'est bien le moins que l'on puisse dire. Installé sur le trône épiscopal de Sault-Sainte-Marie depuis l'érection du diocèse quatre ans plus tôt, Scollard aurait fréquemment maille à partir avec la population franco-catholique de son fief, qui lui rendrait bien, il faut le dire, le peu de sympathie qu'il éprouvait à son égard. Le diocèse de Sault-Sainte-Marie représente l'un des endroits de la province où les tensions, voire les affrontements entre irlando-catholiques et Canadiens français ont été les plus nombreux et les plus acrimonieux pendant les premières décennies du Xx ${ }^{\mathrm{e}}$ siècle ${ }^{4}$. En effet, le tempérament irascible de Scollard rappelait parfois celui de son confrère de London, Michael Francis Fallon, chef de la cabale irlandaise qui contribua puissamment au déclenchement de la crise du Règlement 17 en $1912^{5}$. L'historiographie contient quelques références, certes, aux conflits ethnolinguistiques qui ont secoué le diocèse de Sault-Sainte-Marie pendant le règne de Scollard, les pages de Robert Choquette comptant sans doute parmi les plus substantielles à cet égard, mais aucune étude n'a encore proposé une analyse systématique et détaillée de la question ${ }^{6}$. Or le diocèse de Sault-Sainte-Marie

4. En Nouvelle-Angleterre, les conflits entre catholiques franco-américains et irlandais étaient, eux aussi, particulièrement virulents. Voir Yves Roby, Les FrancoAméricains de la Nouvelle-Angleterre. Rêves et réalités, Sillery, Septentrion, 2000, 530 p. ; Roberto Perin et Matteo Sanfilippo, « Les Conflits ecclésiastiques, 1860-1930 », dans Yves Frenette et al. (dir.), La Francophonie nord-américaine, Québec, Presses de l’Université Laval, 2012, p. 199-205.

5. Sur Fallon, voir la récente étude de Jack Cecillon, Prayers, Petitions, and Protests. The Catholic Church and the Ontario Schools Crisis in the Windsor Border Region, 1910-1928, Montréal et Kingston, McGill-Queen's University Press, 2013, $367 \mathrm{p}$.

6. Voir Robert Choquette, La Foi gardienne de la langue en Ontario, 19001950, Montréal, Éditions Bellarmin, 1987, p. 51-65. Voir aussi Jacques Taillefer, «L'AcFéo à Sudbury, 1910-1927 », dans Guy Gaudreau (dir.), Bâtir sur le roc. De 
représente pour l'historien un cas de figure on ne peut plus intéressant. Découpé à même le territoire du diocèse de Peterborough, il fut rattaché à la province ecclésiastique de Kingston dès sa fondation en 1904. Ainsi, la population franco-catholique, bien que fortement majoritaire à Sault-Sainte-Marie - elle rassemblait $65 \%$ des fidèles en 1901 et encore $58 \%$ vingt ans plus tard ${ }^{7}-$, se voyait d'emblée exclue de la province ecclésiastique d'Ottawa, qui représentait sans contredit le « bastion de la francophonie dans l'Église catholique ontarienne ${ }^{8}$ » et à laquelle seraient pourtant soumis, ailleurs dans le Nord, deux autres diocèses à forte majorité canadienne-française, soit Haileybury (1915) et Hearst (1938) ${ }^{9}$. L'isolement relatif des franco-catholiques de Sault-Sainte-Marie ne les empêcha pas pour autant de tenir tête avec une rare opiniâtreté à l'évêque Scollard, de plus en plus excédé par leur refus de se soumettre à l'autorité épiscopale.

L'étude des conflits ethnolinguistiques qui ont marqué le Nouvel-Ontario au début du $\mathrm{Xx}^{\mathrm{e}}$ siècle permet de mieux prendre la mesure de l'intransigeance qui caractérisait souvent l'attitude des dirigeants nationalistes de l'Ontario français envers leurs coreligionnaires de langue anglaise avant que la hiérarchie vaticane n'intervînt, à la fin des années 1910, pour tenter de refaire l'unité de l'Église canadienne. En rejetant sans ambages la thèse de la langue, « gardienne » de la foi, le Saint-Siège s'attaquait au

l'ACFÉO à l'ACFO du Grand-Sudbury (1910-1987), Sudbury, Éditions Prise de parole, 1994, p. 9-46 ; Guy Courteau, Le Docteur J.-Raoul Hurtubise, M.D, M.P. 40 ans de vie française à Sudbury, Montréal, Éditions Bellarmin, 1971, 136 p. ; Alphonse Raymond, La Paroisse S[ain]te-Anne de Sudbury (1883-1953), Sudbury, Société historique du Nouvel-Ontario, 1953, coll. « Documents historiques », $\mathrm{n}^{\circ}$ 26, 49 p. ; Michel Bock, "Le Vatican et l'AcFÉO au moment du Règlement XVII ", dans Martin Pâquet, Matteo Sanfilippo et Jean-Philippe Warren (dir.), Le Saint-Siège, le Québec et l'Amérique française, Québec, Presses de l'Université Laval, 2013, p. 257-275.

7. Vers la fin du règne de Scollard, en 1931, les Canadiens français étaient passés sous la barre des $50 \%$ de la population catholique du diocèse, mais remontèrent la pente au lendemain de la Seconde Guerre mondiale pour franchir de nouveau le cap des 60 \% (Robert Choquette, La Foi gardienne de la langue en Ontario, 1900-1950, op. cit., p. 55).

8. Ibid., p. 34.

9. Le diocèse de Hailebury fut renommé Timmins en 1938, en même temps que le vicariat apostolique de l'Ontario-Nord, fondé en 1920, devint lui-même le diocèse de Hearst. 
fondement même de l'argumentaire nationaliste canadien-français et contraignait la fronde franco-ontarienne à remettre en question l'union, jugée inviolable jusque-là, des questions nationale et religieuse ${ }^{10}$. À l'instar de leurs compatriotes ailleurs dans la province, les dirigeants canadiens-français de Sault-Sainte-Marie feraient montre, dès lors, d'une plus grande prudence dans leurs tractations avec l'évêque Scollard. Dans les pages qui suivent, nous tâcherons de reconstruire cet affrontement. L'analyse reposera, pour l'essentiel, sur le dépouillement de deux sources, soit les archives de l'AcFÉo, préservées au Centre de recherche en civilisation canadienne-française de l'Université d'Ottawa, et les archives de la nonciature du Canada, préservées aux Archives secrètes du Vatican à Rome. Ces dernières regorgent de documents produits par les différents acteurs de cette histoire, qu'il s'agisse du délégué apostolique, de Scollard lui-même ou encore de ses nombreux détracteurs canadiens-français. Nous montrerons que les tensions ethnolinguistiques, qui allèrent en augmentant au lendemain de la fondation du diocèse de Sault-Sainte-Marie, furent exacerbées dès 1910 dans le contexte des événements qui conduiraient au déclenchement de la crise du Règlement 17 deux ans plus tard, et atteindraient leur paroxysme en 1920, après que l'élite nationaliste d'Ottawa s'en fut mêlée. Au lendemain de la double intervention du Saint-Siège dans la crise scolaire (1916 et 1918), une accalmie relative s'installa entre les deux partis, une accalmie qui était à l'image de la modération idéologique que connaissait, au même moment, l'ensemble de la résistance au Règlement 17. Évitons toute méprise : la méfiance ne disparut pas du jour au lendemain, loin s'en faut. La mort de Scollard en 1934 fut d'ailleurs prétexte à une nouvelle levée de boucliers de la part des dirigeants nationalistes du diocèse de Sault-Sainte-Marie, qui tentèrent encore une fois d'obtenir pour leur diocèse un évêque canadien-français ou, à tout le moins, un évêque qui leur eût été

10. Nous avons analysé ailleurs la contribution de l'intervention du Vatican dans la crise du Règlement 17 à la reconfiguration du champ intellectuel canadienfrançais : Michel Bock, «Le Germe d'un divorce : la langue, la foi et le Règlement 17 », article inédit. 
moins hostile. La nomination de Ralph Hubert Dignan, digne successeur de Scollard, eut tôt fait d'écraser leurs espoirs.

\section{I - JAUGER L'ADVERSAIRE}

\section{A. Un difficile début de règne (1904-1907)}

Au moment de son élévation à l'épiscopat, David Scollard, né à Ennismore (Ontario), en 1862, d'immigrants irlandais, était curé de la paroisse Saint Mary on the Lake à North-Bay, après avoir été vicaire à la cathédrale de Peterborough. Le nouveau diocèse de Sault-Sainte-Marie, qu'érigea Pie x le 16 septembre 1904, recouvrait un immense territoire qui s'étendait du village de Callander jusqu'à la frontière du Manitoba et qui comptait environ 34000 fidèles ${ }^{11}$. Scollard fut nommé à sa tête quatre jours plus tard, nouvelle qui sema la consternation parmi les Canadiens français de la région, car les soupçons qui pesaient sur le nouvel évêque, dont le nom n'était pas inconnu de la population franco-catholique, étaient déjà grands. Sans tarder, le commerçant et député libéral de Nipissing-Ouest à Queen's Park, Joseph Michaud, fit part de ses inquiétudes à l'archevêque d'Ottawa, M ${ }^{\text {gr }}$ Joseph-Thomas Duhamel : «Je puis dire avec connaissance de cause que la moitié de ces Canadiens [du nouveau diocèse de Sault-Sainte-Marie] viennent de la province de Québec et ne parlent ni ne comprennent l'anglais. Les curés eux-mêmes ne parlent que très peu l'anglais et[,] si on peut en juger par les journaux, il est question de nommer un évêque anglais ou irlandais ${ }^{12}$ ! " Michaud demanda, au nom de «plusieurs citoyens importants » des districts de Nipissing et d'Algoma, à rencontrer le délégué apostolique, Donato Sbarretti, pour obtenir des éclaircissements sur la nomination du premier évêque de Sault-Sainte-Marie ${ }^{13}$. Le secrétaire du délé-

11. « Sault Sainte Marie », The Catholic Encylcopedia, http://www.newadvent. org/cathen/13487a.htm (page consultée le 8 janvier 2014) ; diocèse de Sault-SainteMarie, annuaire 2013, http://www.dioceseofsaultstemarie.org/documents/Contact/ 2013-01\%20-\%20Full.pdf (page consultée le 8 janvier 2014).

12. Lettre de Joseph Michaud à Joseph-Thomas Duhamel, 8 novembre 1904, citée dans Paul-François Sylvestre, Nos parlementaires, Ottawa, Éditions L'Interligne, 1986, p. 106.

13. Lettre de Joseph Michaud à Donato Sbarretti, 10 novembre 1904, Asv, ANC, 66.3. 
gué, Alfred Sinnott, acquiesça à sa demande, mais lui répondit péremptoirement, dans le même souffle, que " the new Bishop has been appointed ${ }^{14} \gg$. Michaud n'en fit pas moins le voyage jusqu'à Ottawa pour obtenir de Sbarretti l'entretien demandé, mais fut contraint de rentrer à Sturgeon-Falls bredouille ${ }^{15}$. La décision de la hiérarchie était sans appel.

À l'été 1905, le délégué apostolique effectua lui-même un voyage de trois semaines dans la région des Grands Lacs pour se familiariser avec les particularités du nouveau diocèse. Il est toutefois révélateur que la relation de voyage que consigna son secrétaire, long document de dix-sept pages, ne fait nullement référence aux tensions linguistiques qui avaient déjà commencé à se faire sentir à Sault-Sainte-Marie et qui, de toute évidence, laissèrent Sbarretti de marbre ${ }^{16}$. Pendant ce temps, le nouvel évêque travaillait d'arrache-pied pour que son diocèse fût à la hauteur de ses ambitions. En 1906, il tenta d'obtenir l'annexion à son domaine de l'ensemble du territoire au nord de Sault-SainteMarie, jusqu'à la baie de James, y compris ce qui deviendrait, plus tard, les diocèses de Haileybury (aujourd'hui Timmins) et de Hearst ${ }^{17}$. La population canadienne-française, de son côté, observait les agissements du prélat avec une anxiété croissante. En mai, le quotidien Le Temps d'Ottawa jeta le gant en dénonçant le « mouvement d'anglicisation » qui visait à « faire disparaître [le français] des écoles » de Sudbury, Verner, Warren et SturgeonFalls ${ }^{18}$. Selon le journal, Scollard était directement responsable des déboires que connaissait la population canadienne-française de la région, lui qui avait autorisé l'embauche d'un inspecteur de langue anglaise dans «nos écoles françaises et bilingues » et

14. Lettre d'Alfred Sinnott à Joseph Michaud, 11 novembre 1904, Asv, ANC, 66.3 .

15. Lettre de Joseph Michaud à Donato Sbarretti, 18 novembre 1904, Asv, ANC, 66.4. Malheureusement, aucune trace de l'entretien n'a été conservée.

16. Alfred Sinnott, "Trip up to the Great Lakes, July 24th - Aug. 15th 1905 », [s.d.], Asv, ANC, 66.6.

17. Lettre de David Scollard à Donato Sbarretti, 23 avril 1906, Asv, Anc, 66.7.

18. « La Langue française dans l'Ontario. On essaye de la faire disparaître des écoles », Le Temps, 12 mai 1906, Asv, ANC, 66.4. 
qui avait « fait des misères aux Frères de l'instruction chrétienne qui tenaient trois classes » à Sturgeon-Falls. Le comportement de Scollard ne pouvait guère étonner, précisa toutefois le journal. Curé à North-Bay pendant une douzaine d'années avant de revêtir la toge épiscopale, Scollard s'était toujours opposé à l'embauche d'instituteurs de langue française, en dépit du fait que la majorité de ses paroissiens était canadienne-française. La conclusion que tira Le Temps de ce qu'il percevait comme la campagne antifrançaise de Scollard était alarmante : « [L]e résultat est que nos jeunes Canadiens français de North[-]Bay ne parlent plus guère leur langue maternelle, l'écrive [sic] encore moins ${ }^{19} »$.

Comme ailleurs dans la province, voire en Amérique française, le problème des nominations paroissiales se posa avec acuité dès lors que Scollard assuma la direction du diocèse. Sur ce front, les premières salves furent lancées à Blind-River, lorsque vint le temps de trouver un successeur au curé Patrick Browne, un anglophone bilingue fortement adonné à la boisson, selon la rumeur qui courait ${ }^{20}$. Un groupe de notables dirigé par C. de L. Renaud, marchand-tailleur et secrétaire de la section locale de 1'Union Saint-Joseph, partit à la rencontre du délégué apostolique Sbarretti le 31 août 1907 pour lui « exposer les injustice[s] » commises à l'endroit des Canadiens français de Blind-River dont, en particulier, la nomination de l'abbé McCauley, « un Irlandais d'Irlande qui ne parlait pas le français ${ }^{21}$ ", en remplacement de l'abbé Brown ${ }^{22}$. Les paroissiens espéraient plutôt que Scollard retiendrait la candidature du vicaire de la paroisse, Oscar Racette, futur curé de Verner et proche de Lionel Groulx, mais l'évêque, selon ce qu'en rapporta 1'Ottawa Free Press, avait prétexté l'inexpérience de ce dernier au moment d'arrêter son choix sur

19. Ibid.

20. Rapport, 1907, Centre de recherche en civilisation canadienne-française de l'Université d'Ottawa (dorénavant $\mathrm{CRCCF}$ ), Fonds Association canadienne-française de l'Ontario (dorénavant FACFO), C2/160/2.

21. Ibid.

22. Lettres de C. de L. Renaud à Sbarretti, 20 août 1907 ; d'Alfred Sinnott à C. de L. Renaud, 22 août 1907 ; notes prises par Alfred Sinnott lors d'une réunion avec le délégué apostolique, 31 août 1907, Asv, ANc, 66.9. 
McCauley ${ }^{23}$. À Montréal, le journal de l'ancien ministre libéral Israël Tarte, La Patrie, se lança lui aussi dans la mêlée en publiant une série d'articles sympathiques à l'endroit de McCauley qui, excédé par « la mauvaise volonté [et] l'entêtement de la population canadienne-française ${ }^{24} »$, fut contraint de rendre sa démission et de s'exiler en Illinois après qu'il eut été victime d'intimidation et de menaces de violence physique ${ }^{25}$. Privée de son curé, l'église demeura fermée pendant un long moment, jusqu'à ce que Scollard acceptât, sans doute de guerre lasse, de muter l'abbé J.E. Carrère de Blezard-Valley vers Blind-River, à la grande satisfaction de la population canadienne-française, qui eut, en revanche, beaucoup de mal à digérer les insultes «blessantes » qu'avait lancées à sa figure l'abbé McCauley ${ }^{26}$. La Patrie, de son côté, après avoir publié une entrevue avec Scollard réalisée par son envoyé spécial à Blind-River, encensa le prélat et le félicita de sa « conduite si chrétienne et si généreuse », qu'il fallait même donner en exemple à l'épiscopat irlandais du Maine ${ }^{27}$. L'Ottawa Evening Journal, pour sa part, dénonça ce changement de cap, qui équivalait à une injustice d'autant plus grande que plusieurs paroisses à majorité irlandaise à l'intérieur de l'archidiocèse d'Ottawa avaient accepté de bon gré de se soumettre à l'autorité de curés canadiens-français ${ }^{28}$.

Manifestement, Scollard avait accepté de mettre de l'eau dans son vin après qu'il eut pris conscience de la vigueur des revendications des paroissiens canadiens-français de Blind-River. Tout

23. «Delegation objected to an Irish School Inspector », The Ottawa Free Press, 6 septembre 1907, Asv, Anc, 66.9.

24. «L'église restera fermée demain à Blind[-]River », La Patrie, 7 septembre 1907, Asv, Anc, 66.9.

25. «Les Difficultés religieuses de Blind River», La Patrie, 9 septembre 1907, Asv, Anc, 66.9 ; «L'Évêque de North Bay et l'affaire de Blind River », La Patrie, 10 septembre 1907, p. 7, http://collections.banq.qc.ca/ark:/52327/766366 (page consultée le 9 janvier 2014).

26. «Ils auront un curé canadien-français », La Patrie, 9 septembre 1907, Asv, ANC, 66.9 ; rapport, 1907, CRCCF, FACFO, C2/160/2.

27. "Action énergique », La Patrie, 10 septembre 1907, Asv, Anc, 66.9.

28. Fair Play, « Clergy and People », The Ottawa Evening Journal, 10 septembre 1907, Asv, ANC, 66.19. 
en déplorant que ces derniers eussent choisi d'agiter la presse montréalaise avec cette affaire, il se défendit auprès de l'envoyé spécial de La Patrie de fomenter la dénationalisation de ses fidèles de langue française : « Je suis le plus désireux que les CanadiensFrançais conservent leur langue, parce que je sais qu'alors, ils sont meilleurs catholiques et qu'il est de mon devoir devant Dieu de les aider par tous les moyens qui sont en mon pouvoir à être bon catholiques $^{29}$. » Il précisa tout de même que la «nationalité » des prêtres n'entrait jamais en ligne de compte lorsque venait le temps pour lui de procéder aux nominations paroissiales, car « seules les vertus et les qualités [des candidats étaient] considérées ». Par ailleurs, poursuivit l'évêque, si les Franco-Ontariens de Blind-River ne disposaient d'aucune école bilingue - autre contentieux -, c'est qu'ils n'avaient jamais manifesté le moindre intérêt pour la politique scolaire. Majoritaires, ils auraient pu facilement contrôler la commission scolaire locale, fonder une école bilingue et embaucher des instituteurs franco-catholiques. "Cependant, on refuse de se grouper et de s'entendre : on ne prend même pas la peine d'aller voter, voilà pourquoi on n'a pas d'école bilingue à Blind[-]River ${ }^{30}$. » Autrement dit, le prélat n'y était pour rien, n'en déplût à ses détracteurs. Interrogé à savoir si la nomination de Carrère, qui ne maîtrisait pas l'anglais, poserait problème aux Irlandais de Blind-River, Scollard répondit : « La chose me surprendrait beaucoup. Je crois les connaître, ceux-là, et savoir qu'ils sont très accommodants. » Quelques jours plus tôt, l'évêque avait fait parvenir une lettre semblable à La Presse pour se défendre de l'accusation « calomniatrice et scandalisatrice » d'un résidant de son diocèse qui lui avait reproché, dans les pages du journal, d'avoir orchestré une vaste campagne d'anglicisation à l'encontre de la population canadienne-française ${ }^{31}$.

L'entretien avec l'envoyé spécial de La Patrie avait donné à

29. «L'Évêque de North Bay et l'affaire de Blind River », La Patrie, 10 septembre 1907, p. 7, http://collections.banq.qc.ca/ark:/52327/766366 (page consultée le 9 janvier 2014).

30. Ibid. En majuscules dans le texte.

31. «Lettre de $\mathrm{M}^{\mathrm{gr}}$ Scollard », La Presse, 5 septembre 1907, p. 1, 15. 
Scollard l'occasion de se défouler en contrastant ce qu'il présenta plus ou moins subtilement comme l'intransigeance des Canadiens français avec l'esprit de tolérance et d'ouverture qu'il croyait plutôt déceler chez leurs coreligionnaires irlandais. Cette affaire, on s'en doute bien, eut l'heur de lui laisser un goût fort amer dans la bouche. Il n'était pas au bout de ses peines, toutefois, car les accusations d' « Irishification ${ }^{32}$ » à son endroit continuaient de pleuvoir. À Warren, par exemple, où Scollard avait soutenu que les paroissiens canadiens-français, majoritaires, étaient fort satisfaits de leur curé de langue anglaise, l'abbé Crawley, la presse rapporta qu'il n'en était rien. Plusieurs fidèles avaient même refusé de faire leurs Pâques en guise de protestation contre le peu d'égards qu'on avait à leur endroit, et aussi pour appuyer l'instituteur canadienfrançais du village, qu'une rumeur vouait au congédiement ${ }^{33}$.

\section{B. La fondation de la paroisse Saint-Vincent-de-Paul de North-Bay (1907-1914)}

L'affrontement entre Scollard et ses ouailles de langue française fut ensuite porté au cœur même de son domaine, soit à la cathédrale de North-Bay. À l'été 1908, un incident, trivial en apparence, eut pour conséquence de faire éclater au grand jour des antagonismes linguistiques qui bouillonnaient sous la surface depuis un bon moment. Le 24 juin, une chorale canadienne-française demanda à l'évêque la permission de chanter la grand-messe pour souligner la Saint-Jean-Baptiste. Scollard acquiesça, selon le compte rendu qu'il devait plus tard livrer au délégué Sbarretti de l'affaire, sans toutefois que cela suffit à la chorale, déplora-t-il, qui aurait tenté d'occuper le devant de la scène encore la semaine suivante. De cela, il n'avait jamais été question, se défendit l'évêque, et lorsque la chorale anglaise, arrivée plut tôt, prit sa place habituelle, la chorale canadienne-française aurait tourné les talons et claqué la porte de la cathédrale derrière elle. «[H]ere is

32. " $\mathrm{M}^{\mathrm{gr}}$ Scollard et le français », coupure de presse, [1908], Asv, ANC, 66.15. Il n'a pas été possible, malheureusement, de retracer le journal dans lequel cet article parut.

33. Ibid. 
the cause of the great sensation made by a few hot-heads who love to hear their own voices singing more than they love God or his Holy Church ${ }^{34}$ », conclut Scollard à Sbarretti. Certains esprits mal intentionnés avaient peut-être voulu la monter en épingle, mais « $[t]$ he late choir sensation », ironisa-t-il, n'était guère plus qu'une tempête dans un verre d'eau. Aux dirigeants canadiens-français de North-Bay, l'évêque adressa, de plus, des remarques d'une surprenante condescendance : «Spoiled children no matter how much is done for them by their parents are never satisfied, they are always grumbling and want more. A few French Canadians in North Bay are spoiled children no matter how much is done for them and find fault. But such is human nature ${ }^{35}$. »

Scollard eut beau tenter de dégonfler l'« affaire » de la chorale, les hostilités avaient été déclenchées. L'incident fit sensation dans la presse, dont les comptes rendus, toutefois, ne semblaient pas toujours avoir le mérite de la plus rigoureuse exactitude. Le Montreal Star, par exemple, signala que l'interdiction de chanter avait frappé la chorale le jour même de la Saint-Jean, version des faits qui ne concorde pas avec le récit qu'en avait fait Scollard à Sbarretti. En revanche, le journal conclut avec raison que la controverse menaçait de perturber sérieusement la vie de la communauté, au point où les Canadiens français tentaient désormais d'obtenir une paroisse bien à eux à North-Bay ${ }^{36}$. Le Star avait vu juste, car l'autonomie paroissiale était, en réalité, le véritable enjeu qui se profilait derrière l'affaire de la chorale. L'Evening Citizen d'Ottawa, qui conclut à l' existence d'un «long standing » et « bitter racial dispute ", abonda dans le même sens : "There is a large French Canadian section in the congregation and strong feeling exists between them and the English-speaking members, principally over the language question in the school and church. [...] Exclusive teaching of the English language in separate schools

34. Lettre de David Scollard à Donato Sbarretti, 1908, Asv, ANC, 66.14.

35. Lettre de David Scollard à J.E. Lapointe, 8 juillet 1908, CrCCF, FACFO, C2/159/24.

36. " Church trouble in North Bay. Refusal to allow singing of French mass may disrupt congregation », The Montreal Star, 29 juin 1908, Asv, ANC, 66.14. 
has caused discord and efforts have been made without success to secure a French separate school in North Bay ${ }^{37}$. » En effet, à la question paroissiale s'ajoutait, comme c'était souvent le cas, la question scolaire, le journal relevant les efforts, nombreux mais vains, qu'avait déployés la communauté canadienne-française locale pour obtenir une école séparée française ${ }^{38}$. Scollard, il faut le dire, n'était pas homme à subir l'opprobre sans réagir. Dans le Toronto Star, qui avait publié un billet fort désobligeant à son endroit, puis dans le Catholic Register de Toronto, l'évêque accusa la presse d'avoir grossi l'affaire, se défendit de s'être aliéné l'ensemble de la population canadienne-française et soutint que seuls les membres de la chorale s'étaient dressés contre lui ${ }^{39}$. Dans l'United Canada d'Ottawa, il s'en prit au Temps, qui avait publié, à son avis, « a most [...] scandalous article » qui l'accusait de proscrire l'enseignement du français à l'école séparée de North$\mathrm{Bay}^{40}$. Or il n'en était rien, rétorqua-t-il, car l'enseignement du catéchisme et la préparation à la communion se faisaient aussi bien en français qu'en anglais... ${ }^{41}$

À la fin de 1908, l'affaire de la chorale était encore loin d'être close. Au contraire, le niveau de tension s'éleva de plusieurs crans le 13 décembre lorsqu'un Scollard excédé entra en trombe dans la cathédrale et «publicly rebuked several prominent French Canadian members of the congregation ${ }^{42} \gg$. Le prélat n'y alla pas avec le dos de la cuiller, selon la déclaration statutaire que signèrent,

37. «Parishioners are indignant. Bitter racial dispute in church is long standing. Climax reached over St. Jean Baptiste fete », The Evening Citizen, 29 juin 1908, Asv, ANC, 66.14.

38. Lettre d'Albert Provost à David Scollard, 8 juillet 1908, CrCCF, FACFO, C2/159/24.

39. Lettre de Scollard (sans titre) publiée dans le Catholic Register, $1^{\text {er }}$ juillet 1908, Asv, Anc, 66.14.

40. Il n'a pas été possible, malheureusement, de retracer cet article du Temps, à moins qu'il ne s'agisse de l'article du 12 mai 1906 intitulé « La Langue française dans l'Ontario. On essaye de la faire disparaître des écoles » (cf. note 18).

41. Lettre de Scollard (sans titre) publiée dans l'United Canada, 14 juillet 1908, Asv, AnC, 66.15.

42. "French Canadian members may sue Bishop Scollard ", [titre de journal inconnu], 15 décembre 1908, Asv, ANC, 66.14. 
quelques semaines plus tard, seize paroissiens canadiens-français que le geste avait particulièrement outrés - et qu'un long article publié dans le Dispatch and Tribune de North-Bay peu de temps après l'incident corrobore ${ }^{43}$. Entre autres bassesses, affirmèrent-ils sous serment, Scollard aurait pris à partie six de ses détracteurs en les affublant de surnoms injurieux devant toute la communauté des fidèles rassemblée. De «William Le Jaune » (William Pardiac), il aurait ridiculisé l'infirmité dont il souffrait à la jambe, tout en lui reprochant de payer ses taxes scolaires aux écoles publiques. «Octavius Maximum » (Octave Gauthier) était, pour sa part, coupable de parjure, car il soutenait, au mépris de la vérité, que l'évêque, qui menaçait de le faire mettre sous les verrous ${ }^{44}$, avait autorisé la chorale à chanter la messe le dimanche suivant la Saint-Jean. « Moïse » (le docteur J. A. Bédard), « Lord Nelson » (Nelson Aubry) et « le Petit Wilfrid» (Wilfrid Aubry) s'étaient, eux aussi, rendus coupables de plusieurs crimes, y compris d'avoir gravement manqué de justice envers le clergé irlandais. Son coup le plus foudroyant, Scollard l'asséna toutefois à «Aaron » (l'avocat J.E. Lapointe) qui, " venu de Hull or Hell [sic]», était l'auteur, à ses yeux, des turpitudes les plus infamantes. Non seulement « tenait[-il] un temple d'esprit sur la rue Front où il prêchait continuellement la doctrine de l'enfer », il répétait à qui voulait bien l'entendre que « les prêtres, les évêques et le pape ne [pouvaient] point être bons s'ils n['étaient] pas Canadiens Français [sic] $»^{45}$. Scollard conclut ce concentré de colère en exhortant la communauté à « ne pas encourager ces gens, ni même les visiter », c'est-à-dire en les mettant au ban. Dans le même souffle, il

43. La déclaration statutaire, signée le 31 janvier 1909, fut expédiée au délégué Sbarretti le 5 avril 1909. Il comportait les seize signatures suivantes : A.T. Arlène, J.ArthurMorin Jr.,AlbertProvost, M. Guenette, E.Labrèche,A. Gauthier, J.E. Beaudette, E. Bédard, D. Gauthier, Edmond Boyer, A.J. Roujier, A. Couturier, Léo Lefebvre, J. Beaudette, D.D. Martel, P.O. Leclair (Asv, ANC, 66.16). L'article du Dispatch and Tribune, «Bishop Scollard denounces sowers of discord», paru le 17 décembre 1908, fut consulté aux deux endroits suivants : Asv, ANC, 66.16; CRCCF, FACFO, C2/159/24.

44. Lettre de David Scollard à J.E. Lapointe, 8 juillet 1908, CrCcF, Facfo, C2/159/24.

45. Déclaration statutaire, signée le 31 janvier 1909, et expédiée au délégué Sbarretti le 5 avril 1909, Asv, ANC, 66.16 (en majuscules dans le texte). 
injuria la Société Saint-Jean-Baptiste (vraisemblablement celle d'Ottawa), le Club canadien de North-Bay où se réunissaient ses détracteurs, de même que « leur chère Province de Québec ».

Les paroles de Scollard avaient claqué comme un fouet. Les agitateurs qui avaient ainsi attiré son mépris, malgré les surnoms qu'il avait utilisés pour les désigner, étaient facilement reconnaissables, soutenaient les seize signataires de la déclaration statutaire, ce qui leur avait occasionné des «pertes considérables dans leurs professions, leurs réputations, commerce, etc. [sic]». L'un d'eux, J. E. Lapointe, eut même l'audace de demander au délégué apostolique la permission d'intenter une poursuite de $25000 \$$ contre l'évêque ${ }^{46}$. Inutile de préciser que Sbarretti rejeta vigoureusement la requête, « qui n'était pas digne d'être prise en considération par l'autorité ecclésiastique ${ }^{47} »$. Vincent, piqué au vif, rétorqua au délégué avec une défiance peu commune que sa réponse l'avait « profondément blessé », que la demande qu'il lui avait présentée était «sérieuse, respectueuse de l'autorité ecclésiastique », et qu'il ne voyait désormais aucune utilité à lui remettre les documents qu'il avait préparés en guise de préparation pour une éventuelle poursuite ${ }^{48}$. Pour sa part, l'infortuné Pardiac, que Scollard avait accusé de financer les écoles publiques, dut même produire sa propre déclaration statutaire expliquant qu'il n'avait eu d'autre choix que d'y envoyer sa fille, l'école séparée de North-Bay fonctionnant exclusivement en anglais ${ }^{49}$.

À Ottawa, l'élite nationaliste n'était pas demeurée indifférente à cette affaire. La Société Saint-Jean-Baptiste, par exemple, contribua à l'organisation d'une manifestation au Monument national en guise d'appui aux compatriotes de North-Bay ${ }^{50}$. L'Association canadienne-française d'éducation d'Ontario (AcFÉo), fondée en

46. Ibid. ; «French Canadian members may sue Bishop Scollard», [titre de journal inconnu], 15 décembre 1908, Asv, ANC, 66,14.

47. Lettre de Donato Sbarretti à J.U. Vincent, 8 avril 1908, Asv, Anc, 66.16.

48. Lettre de J.U. Vincent à Donato Sbarretti, 16 avril 1908, Asv, Anc, 66.16.

49. Déclaration statutaire de William Pardiac devant le juge de paix Onésime Larocque, 31 janvier 1909, Asv, ANC, 66.16.

50. «Clergy come in for criticism », The Ottawa Journal, 21 décembre 1908, Asv, ANC, 66.14; lettre de J.A. Vincent à Sbarretti, 5 avril 1909, Asv, ANC, 66.16. 
janvier 1910, et le journal Le Droit, qui vit le jour trois ans plus tard, se mirent aussi de la partie lorsque le père oblat Charles Charlebois expédia au nouveau délégué apostolique, Pellegrino Stagni, un volumineux dossier contenant plusieurs pièces à conviction en lien avec l'affaire de North-Bay ${ }^{51}$. Le dossier comprenait, entre autres choses, la correspondance que s'étaient échangée Scollard et J. E. Lapointe autour de l'incident de la chorale, l'évêque y déplorant le bruit qu'il avait provoqué dans la presse protestante, une lettre de Scollard au curé de Chelmsford, Stéphane Côté, dans laquelle il s'opposait à l'érection d'une école modèle bilingue à Sturgeon-Falls (communication pratiquement identique à celle qu'il expédia au même moment au ministre de l'Éducation, Robert Pyne ${ }^{52}$ ), ainsi qu'une autre lettre, sardonique et menaçante, qu'il avait fait parvenir au député provincial de Nipissing, Henri Morel, lequel se préparait, en janvier 1910, à participer au grand Congrès des Canadiens français de l'Ontario à Ottawa :

As you will go down to the French Canadian congress in Ottawa, I presume as a great representative French Canadian ready to die for their cause, and Monseigneur Scollard will perhaps be criticized at the very congress for being an enemy of French Canadians, notwithstanding the fact that Monseigneur Scollard struggled with all his might against the French Canadian members of Nipissing and Sturgeon Falls in order to obtain Registrarship of North Bay for a French Canadian Catholic. [...] Mark my words, you will pay dearly for this later on $^{53}$.

Le sens de ce commentaire ne se laisse pas facilement saisir. Scollard semblait reprocher à un groupe de Canadiens français incluant Morel d'avoir entravé ses efforts pour favoriser l'embauche d'un des leurs dans un poste administratif d'une certaine importance. Le père Charlebois croyait utile néanmoins d'inclure la lettre 80.5 .

51. Lettre de Charles Charlebois à Pellegrino Stagni, 16 avril 1913, Asv, ANC,

52. Lettre de David Scollard à Robert Pyne, 3 septembre 1909, CRCCF, FACFO, $\mathrm{C} 2 / 160 / 4$.

53. Lettre de David Scollard à Henri Morel, 12 janvier 1910, annexée à une lettre de Charles Charlebois à Pellegrino Stagni, 16 avril 1913, Asv, ANC, 80.5. 
parmi les pièces à conviction qu'il destinait au délégué apostolique, ce qui laisse supposer qu'il y avait anguille sous roche, du moins à ses yeux. Stagni, qui prenait peu à peu conscience de la complexité de la question religieuse (et nationale) au Canada, demanda à Scollard de lui expliquer les raisons pour lesquelles il s'opposait tant à la création d'une paroisse de langue française à North-Bay ${ }^{54}$. L'évêque de Sault-Sainte-Marie lui indiqua, pour toute réponse, que la question ne s'était jamais posée et que, dans l'éventualité où le besoin d'une nouvelle paroisse se ferait sentir, l'on réfléchirait à la question linguistique le moment venu ${ }^{55}$. Or le moment vint rapidement, car à peine un mois plus tard, Le Droit annonçait avec satisfaction que Scollard avait enfin donné son assentiment, quoique sans doute à contrecœur, à l'érection d'une paroisse canadienne-française à North-Bay, après que lui fut parvenue une pétition signée par plus de 300 chefs de famille dirigés par le docteur J. A. Bédard, « Moïse », l'un de ceux que l'évêque avait conspués du haut de sa chaire en décembre $1908^{56}$. Gaétan Gervais rapporte que, selon une légende « amusante mais invérifiable ", le prélat aurait décidé, dans un geste rempli de cynisme et d'amertume, de placer la nouvelle paroisse sous la protection de saint Vincent de Paul, le patron des pauvres, car il la croyait « vouée à une inéluctable pauvretée $e^{57}$ »..

\section{II - L'EXACERBaTION DES INIMITIÉS}

\section{A. La campagne pour déloger Scollard (1908 et 1913)}

L'époque se montrait querelleuse. Au tournant des années 1910, l'impérialisme britannique ralliait une bonne partie de l'opinion canadienne-anglaise, qui réclamait, avec une insistance croissante, que l'on supprimât le français des écoles de la province. De part

54. Lettre de Pellegrino Stagni à David Scollard, 15 avril 1913, Asv, Anc, 80.5.

55. Lettre de David Scollard à Pellegrino Stagni, 16 avril 1913, Asv, Anc, 80.5.

56. «La Nouvelle Paroisse canadienne-française » Le Droit, 20 mai 1913, Asv, ANC, 80.5.

57. Gaétan Gervais, «Les Paroisses de l'Ontario français, 1767-2000 », Cahiers Charlevoix, $\mathrm{n}^{\circ} 6$ (2004), p. 161-162. La paroisse Saint-Vincent-de-Paul vit le jour officiellement l'année suivante, en 1914. 
et d'autre, on durcissait sa position. Dans ce contexte, le règne de Scollard était devenu intolérable, aux yeux de plusieurs. Non seulement s'était-il attiré les foudres de ses propres ouailles, il avait aussi suscité le mécontentement de l'épiscopat canadienfrançais, lequel entreprit, en 1908, une vaste campagne pour tenter de le déloger du trône de Sault-Sainte-Marie. Il ne s'agissait pas, toutefois, de faire tomber Scollard dans la disgrâce en obtenant son renvoi, mais plutôt de convaincre la hiérarchie vaticane de lui offrir une promotion on ne peut plus alléchante en le mutant au siège métropolitain de Toronto, l'archevêque Denis O'Connor ayant annoncé sa démission. Élégante, cette solution avait le mérite de mettre l'évêque de Sault-Sainte-Marie hors d'état de nuire, sans toutefois lui faire subir l'opprobre d'une répudiation. L'archevêque de Montréal, Paul Bruchési, voyait « chez $M^{\text {gr }}$ Scollard un ensemble de qualités qui en [faisaient] [...] 1 'homme de la situation dans la capitale d'Ontario ${ }^{58} »$. L'occasion était belle de faire d'une pierre, trois coups, expliqua-t-il au délégué Sbarretti, car la mutation de Scollard à Toronto eût permis de doter le diocèse de Sault-Sainte-Marie, où les franco-catholiques constituaient la majorité, d'un évêque canadien-français - « mais sachant parfaitement l'anglais »- et de le rattacher à la province ecclésiastique d'Ottawa qui ne comptait, pour l'heure, qu'un seul suffragant (celui de Pembroke, en l'occurrence). Depuis Saint-Boniface, l'archevêque Adélard Langevin abonda dans le même sens dans une longue lettre expédiée au préfet de la propagande, le cardinal Girolamo Maria Gotti. Non seulement la population franco-catholique de Sault-Sainte-Marie méritaitelle un évêque canadien-français, il était impératif qu'on annexât le diocèse à la province ecclésiastique d'Ottawa, où plus aucun conflit n'aurait sévi entre les questions religieuse et nationale. La « race française » était la principale force du catholicisme dans le Nouvel-Ontario, souligna Langevin à grands traits, et, comme l'avait prédit avec tant de justesse Rameau de Saint-Père, au siècle

58. Lettre de Paul Bruchési à Donato Sbarretti, 15 janvier 1908, CRCCF, FACFO, C2/153/10. 
dernier, la « conquête silencieuse » de la «province anglaise et protestante d'Ontario » était bel et bien en marche :

En conséquence, Éminence, il me semble clair qu'il est dans l'intérêt de l'Église catholique de favoriser le groupement des catholiques de langue française sous des évêques qui les comprennent, les encouragent et jouissent de leur confiance. C'est comme conclusion de ces faits et de ces considérations soumis à l'examen de Votre Éminence que j'ose exprimer le vœu ardent de voir le diocèse de Sault[-]Sainte[-]Marie rattaché à la province ecclésiastique d'Ottawa, afin de fortifier la situation de Sa Grandeur Monseigneur Duhamel en butte, depuis de longues années, à une pression très forte de la part de l'épiscopat de langue anglaise d'Ontario, pour l'amener à se donner un prêtre de langue anglaise comme son successeur.

Il me semble, Éminence, que j'obéis à un sentiment de foi et non à un nationalisme étroit en prenant la liberté de vous écrire ces lignes en toute confiance ${ }^{59}$.

L'archevêque d'Ottawa fit lui-même connaître son avis au cardinal Gotti sur la succession d'O'Connor en louant le « grand calme » et la «modération admirable » de Scollard, qui possédait un « ensemble de qualités » faisant de lui le «plus digne des trois candidats » pressentis par Rome - les deux autres étant l'évêque de London, Fergus Patrick McEvay, et le curé de Sainte-Catherine's, D. Morris ${ }^{60}$. Comme ses confrères de Montréal et de SaintBoniface, Duhamel espérait qu'avec l'éventuel départ de Scollard, le diocèse de Sault-Sainte-Marie serait rattaché à la province ecclésiastique d'Ottawa. Certes, la population catholique y était majoritairement canadienne-française, mais il y avait plus. Le territoire actuel de Sault-Sainte-Marie avait appartenu au diocèse d'Ottawa jusqu'en 1878, au moment où Duhamel, alors simple évêque, avait lui-même accepté de le céder au vicariat apostolique du Canada septentrional, devenu plus tard le diocèse de Peterborough à partir duquel fut découpé le diocèse de Scollard

59. Lettre d'Adélard Langevin à Girolamo Maria Gotti, 16 février 1908, CRCCF, FACFO, C2/153/10.

60. Lettre de Joseph-Thomas Duhamel à Girolamo Maria Gotti, 2 février 1908, CRCCF, FACFO, C2/100/4. 
en 1904. « Ce serait rendre, en quelque sorte, cette partie à son premier titulaire, si le diocèse du Sault-Sainte-Marie était attaché à la province ecclésiastique d'Ottawa ${ }^{61}$ », fit-il valoir à Gotti en soulignant qu'il eût été « très facile de présenter une liste de candidats canadiens-français, tout à fait dignes de l'épiscopat, connaissant les deux langues » pour succéder à Scollard. Rien de plus normal, autrement dit, que de ramener le diocèse de SaultSainte-Marie dans le giron d'Ottawa, son milieu naturel ${ }^{62}$.

La nouvelle tomba au printemps 1908, anéantissant les espoirs des évêques canadiens-français, lorsque le Saint-Siège nomma au siège archiépiscopal de Toronto non pas Scollard, mais plutôt McEvay. On avait à peine eu le temps d'en mesurer les conséquences que, déjà, l'opinion se perdait de nouveau en conjectures, cette fois sur la succession de McEvay à London. À Sudbury, Jean-Étienne (« Stephen ») Fournier, le premier maire de la ville élu en 1893, demanda à être reçu en audience par le délégué apostolique à Ottawa pour discuter de la mutation de Scollard à London et de son éventuel remplaçant à Sault-SainteMarie. Fournier avait vraisemblablement été de la délégation qu'avait dirigée le député Joseph Michaud auprès de Sbarretti au moment de la création du diocèse de Sault-Sainte-Marie en 1904. Depuis, lui expliqua-t-il, « [1]es faits [n'étaient] point changés ». Les Canadiens français, dont les rangs n'avaient pas diminué, étaient « toujours très désireux d'avoir un évêque de leur nationalité » capable de comprendre « mieux qu'aucun autre leurs besoins spirituels et temporels », un évêque « qui saura[it] diriger l'éducation et l'instruction dans leur langue maternelle des enfants fréquentant les écoles catholiques et bilingues » que l'on s'efforçait de multiplier dans le Nouvel-Ontario. « Par ce moyen, nous espérons conserver la langue française dans nos

61. Ibid.

62. Duhamel s'entretint aussi de la mutation possible de Scollard vers Toronto avec Langevin, de même qu'avec l'archevêque de Québec, Louis-Nazaire Bégin, un ami fidèle de l'éventuelle résistance franco-ontarienne au Règlement 17 (lettres de Joseph-Thomas Duhamel à Adélard Langevin, 5 février 1908, et à Louis-Nazaire Bégin, 5 février 1908, CRCCF, FACFO, C2/153/10 ; voir aussi Michel Bock, « Le Vatican et l'ACFÉO au moment du Règlement XVII », op. cit., p. 257-275). 
familles et rendre la foi plus forte et plus vivace parmi le peuple en général ${ }^{63}$. 》 Le délégué lui fit comprendre plutôt laconiquement que, malgré les rumeurs que colportaient les journaux, le nouvel évêque de London n'avait pas encore été nommé, laissant entendre par là que le moment n'était pas venu d'envisager la succession de Scollard à Sault-Sainte-Marie ${ }^{64}$. En fin de compte, Rome rejeta la candidature de l'évêque nord-ontarien, au grand dam des fidèles canadiens-français de son diocèse. À London, la population franco-catholique ne savait plus à quel saint se vouer, car au lieu de Scollard, on lui demanda plutôt d'accueillir Michael Francis Fallon à la direction du diocèse...

Cette première tentative pour déloger Scollard avait été infructueuse, certes, mais les dirigeants nationalistes de l'Ontario français remirent l'épaule à la roue cinq ans plus tard, lorsque vint le temps de trouver un successeur à l'évêque de Peterborough, Richard O'Connor, décédé le 23 janvier 1913. Depuis Ottawa, l'AcFéo intervint moins d'un mois plus tard auprès de l'archevêque de Québec, Louis-Nazaire Bégin, pour obtenir son appui à une possible mutation de Scollard vers Peterborough, mutation qu'O'Connor avait lui-même souhaitée, à ce que l'on rapportait.

De plus, Monseigneur Scollard aurait dit à l'archevêché d'Ottawa ces jours derniers, et devant témoins, qu'il vaudrait mieux qu'il y eut [sic] un évêque canadien-français à la tête du diocèse du Sault Ste Marie [sic] et de fait il nous est pénible de constater que le peu de confiance et de respect qu'ont les diocésains pour leur évêque, occasionnés par les sorties de $\mathrm{Sa}$ Grandeur en chaire et son manque de tenue, éloigne les fidèles de l'Église.

[...] Ce que nous demandons à Votre Grandeur, c'est de faire reconnaître la place que les nôtres devraient occuper dans la hiérarchie catholique pour le plus grand bien de la religion et de la race ${ }^{65}$.

63. Lettre de S. Fournier à Donato Sbarretti, 28 mai 1908, Asv, ANC, 66.12.

64. Lettre de [Sbarretti] à S. Fournier, 31 mai 1908, Asv, Anc, 66.12.

65. Lettre du secrétaire de l'ACFÉo à Louis-Nazaire Bégin, 20 février 1913, CrCCF, Facfo, C2/152/2. 
Visiblement, la stratégie n'était plus la même qu'en 1908. Si, à l'époque, les évêques canadiens-français semblaient s'être donné la consigne d'encenser Scollard afin d'obtenir sa mutation à Toronto, l'ACFÉO, à présent, mettait plutôt de l'avant les injustices qu'il avait commises envers la population canadienne-française de son diocèse. Le directeur du Droit, le père Charlebois, en rajouta. Personne n'eût jamais songé à nommer un évêque français en Italie, fit-il valoir auprès du délégué apostolique Stagni. De même, les fidèles de Sault-Sainte-Marie méritaient bien qu'un des leurs occupât les plus hautes fonctions ecclésiastiques du diocèse, d'autant plus que l' « antipathie bien caractérisée » qui souillait les relations entre Canadiens français et Irlandais était, à ses yeux, un « fait indéniable ${ }^{66}$. Charlebois dressa la très longue liste des torts dont s'était rendu coupable Scollard envers les Canadiens français de son diocèse : le prélat prétextait l'universalité de l'Église pour s'opposer au principe des paroisses nationales ; il appuyait sans ménagement le Règlement 17, adopté l'année précédente, et voyait d'un mauvais œil ceux qui le combattaient; il estimait les prérogatives épiscopales supérieures au droit naturel des parents de choisir la langue de leur progéniture ; il s'était opposé à la fondation d'une école de pédagogie bilingue à Sturgeon-Falls ; il parlait des Canadiens français « avec mépris » et raillait leurs hommes publics ainsi que leurs journaux, alors que la presse protestante demeurait, elle, à l'abri de ses salves; il aurait « jou[é] de ruse pour la nomination de prêtres aux cures et par des moyens pris afin d'embrouiller les Canadiens français », etc. Pour toutes ces raisons, Scollard devait plier bagage, conclut Charlebois, qui présenta même son éventuelle mutation au diocèse de Peterborough, «plus ancien », « mieux organisé » et «plus riche » que Sault-Sainte-Marie, comme une sorte de promotion qui aurait permis à la hiérarchie de protéger les apparences.

La réponse que fit Stagni à Charlebois nous est inconnue. Il appert toutefois que le secrétaire de la Sacrée Congrégation

66. Lettre (mémoire) de Charles Charlebois à Pellegrino Stagni, avril 1913, Asv, Anc, 80.5. 
consistoriale, le cardinal Gaetano de Lai, après avoir été saisi de l'affaire, ne jugea pas utile de déplacer Scollard vers Peterborough, ne voyant pas de raisons suffisamment graves pour poser un geste dont l'objectif à peine voilé aurait été de lui montrer la porte ${ }^{67}$. Le Saint-Siège nomma plutôt l'abbé Michael Joseph O'Brien au trône épiscopal de Peterborough, au grand dam, encore une fois, des détracteurs canadiens-français de l'évêque de SaultSainte-Marie, dont la volonté de fer ne donnait aucun signe de fléchissement. Au contraire, les controverses dont il faisait l'objet et les critiques qu'il s'attirait continuaient de se multiplier. Le Règlement 17 ayant été adopté l'année précédente, il crut de son devoir, par ailleurs, de signaler son appui plein et entier à la politique scolaire ontarienne au moment où le député de SaultSainte-Marie, William Hearst, fut nommé premier ministre de la province. Dans une lettre confidentielle qu'il lui fit parvenir à peine quelques jours après qu'il eut succédé à James Whitney, décédé deux semaines plus tôt, il le mit en garde contre les « extrémistes » canadiens-français d'Ottawa qui n'avaient pas su apprécier à leur juste valeur la générosité et la magnanimité que leur avait témoignées son prédécesseur :

We are all proud that one from the illimitable north sits now in the Premier's chair. The late Premier was just and fair to all classes and creeds, he was not just generous to the French Canadian people, and yet many of them, misled by extremists for the most part in Ottawa, failed to appreciate his generosity. His attitude on the bi-lingual question was to my mind the correct one, and I can only express the wish that you may be firm also on this question, and the agitation promoted by those Ottawa extremists will sooner or later peter out and the French people will pursue a saner course obeying the just laws and regulations of the Province ${ }^{68}$.

67. « Rapport du cardinal de Lai à propos d'un possible transfert de Scollard à Peterborough », 19 avril 1913, Asv, ANC, 80.5.

68. Lettre de David Scollard à William Hearst, 6 octobre 1914, CRCCF, FACFO, C2/160/2. Nous avons consulté ce qui est vraisemblablement une retranscription de cette lettre de Scollard à Hearst et dont il n'a pas été possible, malheureusement, de vérifier l'authenticité. 
Quelques années plus tôt, en 1910, Scollard avait d'ailleurs participé à une réunion des évêques des provinces ecclésiastiques de Kingston et de Toronto convoquée pour discuter de l'avenir de l'enseignement catholique en Ontario à la lumière de « l'agitation qui a[vait] atteint son point culminant au [récent] Congrès canadienfrançais d'Ottawa », congrès qui avait donné naissance, rappelons-le, à 1'AcFÉO ${ }^{69}$. Les évêques avaient délégué Michael Fallon, qui s'était exécuté dès le lendemain, pour rencontrer le premier ministre Whitney et lui signifier leur « opposition complète aux demandes dudit Congrès en matière d'enseignement ${ }^{70} \gg$. La rencontre des évêques avait été gardée secrète jusqu'en $1917^{71}$, mais lorsque l'ACFÉO en eut vent, elle imputa derechef l'adoption du Règlement 17 aux agissements du lobby irlandais, dont Scollard était clairement une des têtes d'affiche ${ }^{72}$.

\section{B. L'affaire de Sudbury (1915-1920)}

En 1915, les tensions ethnolinguistiques en Ontario et au Canada n'avaient pas encore tout à fait atteint leur paroxysme, mais elles s'en rapprochaient. La crise du Règlement 17 battait son plein depuis trois ans, tandis que la Première Guerre mondiale, qui avait éclaté l'année précédente, divisait de plus en plus l'opinion canadienne après une période initiale d'unanimité relative autour de la nécessité pour le Canada d'y participer militairement. En 1917 fut déclenchée la crise de la conscription, l'une des crises politiques les plus graves qu'ait connues le pays depuis la Confédération de 1867. C'est en gardant ce contexte politique en tête qu'il faut considérer la controverse que généra la division de la paroisse Sainte-Anne-des-Pins de Sudbury entre 1915 et 1920. Fondée par les jésuites en 1883, Sainte-Anne était l'une des plus anciennes paroisses du Nouvel-Ontario. Devenue mixte, les Cana-

69. Robert Choquette, Langue et religion. Histoire des conflits anglo-français en Ontario, Ottawa, Éditions de l'Université d'Ottawa, 1977, p. 97.

70. Cité dans ibid., p. 96.

71. Ibid., p. 209-210.

72. Lettre de Philippe Landry à Charles Hugh Gauthier, 19 mai 1917, CRCCF, FACFO, C2/153/2. 
diens français y cohabitaient, en 1915, avec leurs coreligionnaires irlandais, cohabitation que l'exiguïté des lieux rendait toutefois de plus en plus difficile, sans parler du désir qu'éprouvaient les paroissiens de langue française d'avoir une paroisse bien à eux. Dans une lettre pastorale qu'il fit lire aux fidèles le 27 juillet 1915 , Scollard, bon prince, donna sa bénédiction à la division de SainteAnne-des-Pins et, par le fait même, à l'autonomie paroissiale de la population franco-catholique :

Les aspirations et les désirs du peuple canadien-français de Sudbury d'avoir une église où la langue française, et seulement la langue française serait parlée ont été portés à ma connaissance il y a plus d'un an, par les Pères [jésuites] de Sudbury. Après avoir consulté les principaux laïques canadiens-français de Sudbury, je me suis convaincu que la grande majorité des Canadiens français de Sudbury, désire avoir une église qui soit son église propre.

Après avoir dûment considéré la chose, j'ai décidé de me rendre aux désirs des Canadiens français et de leur accorder la séparation ${ }^{73}$.

Le ton et le vocabulaire de Scollard laissaient clairement transparaître une pointe de cynisme, mais cela importait peu aux paroissiens de langue française, qui se réjouirent de la nouvelle. Les Irlandais quitteraient les lieux dès qu'ils auraient financé la construction de la nouvelle église Saint-Joseph (renommée Christ the King plus tard), une hypothèque de 8100 \$ ayant été contractée à cette fin, tandis que les Canadiens français assumeraient seuls la dette de 42000 \$ qu'avait accumulée la paroisse Sainte-Anne au fil des années. Le prix à payer pour l'autonomie paroissiale pouvait paraître élevé, sous certains aspects, mais la population franco-catholique accepta les conditions dictées par Scollard sans rechigner. Après tout, l'évêque avait clairement fait comprendre que l'actuel terrain de Sainte-Anne ne serait pas démembré et que la nouvelle église Saint-Joseph serait érigée ailleurs ${ }^{74}$. Tout

73. Lettre pastorale de David Scollard lue en chaire le 27 juillet 1915 aux paroissiens de Sainte-Anne-des-Pins, Asv, Anc, 80.10.

74. Lettre de David Scollard à François-Xavier Descoteaux, 11 avril 1915, CRCCF, FACFO, C2/218/1 ; lettre de David Scollard à François-Xavier Descoteaux, 
semblait aller pour le mieux. Or, plus d'un an plus tard, les sommes recueillies pour le financement de l'église irlandaise restaient maigres ${ }^{75}$. Le bruit commença dès lors à se répandre que, devant le mécontentement des anglo-catholiques, qui jugeaient trop excentré le terrain retenu pour la construction du nouveau lieu de culte, Scollard était revenu sur sa décision de ne pas scinder le terrain de la paroisse-mère. Les Canadiens français se mobilisèrent sans tarder en obtenant un avis légal sur les limites du terrain de Sainte-Anne, ainsi que sur le sens de la lettre pastorale du 27 juillet 1915 dans laquelle Scollard leur en avait fait don ${ }^{76}$. Pris d'inquiétude, le curé de Sainte-Anne, François-Xavier Descoteaux, tenta de vérifier auprès de Scollard la véracité des racontars qui circulaient. « Si ces rumeurs ne sont que des canards », lui auraient affirmé ses paroissiens, « nous aurons la paix ; si ces rumeurs sont fondées, nous devrions avoir un comité chargé de faire valoir nos intérêts devant Sa Grandeur ${ }^{77}$ ». La menace était à peine voilée : si Scollard revenait sur sa parole, il trouverait les paroissiens canadiens-français sur son chemin.

L'évêque de Sault-Sainte-Marie ne se laissait pas facilement intimider. Au père Descoteaux, qui lui paraissait « very much agitated over affairs in Sudbury », il rétorqua péremptoirement que le terrain de Sainte-Anne appartenait non pas aux paroissiens, mais à l'autorité épiscopale, qui était libre d'en disposer à sa guise ${ }^{78}$. De toute manière, son prédécesseur, le père Julien Paquin, avait lui-même proposé, à l'époque, que l'on scindât le terrain de Sainte-Anne dans le dessein d'y ériger la nouvelle paroisse Saint-Joseph. En parcourant ce mot de Scollard, le père Descoteaux sortit de ses gonds : « Votre lettre débute en insinuant que je suis excité au sujet des affaires de Sudbury. Quand on se

11 août 1915, Asv, ANC, 80.10.

75. Lettre de David Scollard à François-Xavier Descoteaux, 11 novembre 1916, Asv, ANC, 80.10.

76. Bernardin Boutet, avis légal, 17 juillet 1918, Asv, ANC, 80.10.

77. Lettre de François-Xavier Descoteaux à David Scollard, 17 juillet 1918, Asv, ANC, 80.10. 80.10 .

78. Lettre de David Scollard à François Descoteaux, 28 avril 1919, Asv, ANC, 
sent menacé, c'est de la prudence [que] d'avoir peur. Vous me permettrez bien de m'intéresser autant aux Canadiens français de Sudbury que d'autres aux Irlandais de Sudbury ${ }^{79} \gg$. Scollard avait lui-même rejeté, à l'époque, le projet du père Paquin, qui, de toute façon, «n'avait pas le monopole de la sagesse et qui n'a[vait] jamais eu la prétention de penser pour tous les Jésuites ». À quoi servait de l'évoquer maintenant ? Certes, les Canadiens français de Sainte-Anne n'avaient pas eux-mêmes acheté le terrain de l'église, mais ils le revendiquaient en vertu du don que leur en avait fait l'évêque dans sa lettre pastorale du 27 avril 1915. Ils avaient, de surcroît, accepté et rempli « sans murmurer et sans protester » les conditions pour le moins sévères qu'il leur avait imposées : en trois ans, la dette de 42000 \$ de leur paroisse avait déjà fondu de près de $40 \%$ et se chiffrait maintenant à $26000 \$$. Sainte-Anne manquait-elle de générosité envers Saint-Joseph? La cathédrale de North-Bay s'était-elle montrée plus magnanime, quatre ans plus tôt, envers les Canadiens français qui avaient érigé, avec les moyens du bord, la paroisse Saint-Vincent-de-Paul ? L'essentiel était que l'évêque leur avait fait une promesse « par un acte solennel, après consultation et délibération », et voici qu'il revenait sur sa parole. «Vous me pardonnerez de vous avoir adressé ces lignes que j'ai écrites non pas comme agitateur, mais comme prêtre ayant charge d'âmes, selon ma conscience, parce que la chose me paraissait juste et nécessaire ${ }^{80} »$. Quelques jours plus tard, le curé de Sainte-Anne était remercié de ses services ${ }^{81}$.

Aux grands maux les grands remèdes. Le temps était venu, encore une fois, d'en appeler à la hiérarchie romaine. Le 20 mai 1919, le docteur J.-Raoul Hurtubise et le quincailler Félix Ricard, deux des principaux dirigeants de la lutte contre le Règlement 17 à Sudbury, se rendirent discrètement à Ottawa pour rencontrer le nouveau délégué apostolique, Pietro di Maria, et lui remettre en mains propres un long mémoire sur l'affaire de la paroisse

79. Lettre de François-Xavier Descoteaux à David Scollard, $1^{\text {er }}$ mai 1919, Asv, ANC, 80.10.

80. Ibid.

81. Guy Courteau, Le Docteur J.-Raoul Hurtubise, op. cit., p. 49. 
Sainte-Anne ${ }^{82}$. En revenant sur sa parole, Scollard risquait de « rabaisser publiquement sa dignité », « causer une dissatisfaction [sic] générale chez les Canadiens français » et « raviv[er] les inimitiés profondes » entre les deux groupes ethnolinguistiques. Le jour même de la rencontre entre Hurtubise, Ricard et di Maria, La Presse s'empara de l'affaire en publiant un long article qui résumait les grandes lignes de ce « malentendu assez grave, qui [pouvait] prendre d'un instant à l'autre toutes les proportions d'un conflit aigu » entre Scollard et « les nôtres de la ville de Sudbury $\gg{ }^{83}$. L'article prenait clairement le parti des Canadiens français, mais n'en provoqua pas moins le mécontentement de la délégation franco-sudburoise à Ottawa, qui craignait d'en essuyer les plâtres. Ricard, qui avait voulu agir dans la discrétion, fit comprendre au directeur du Droit, Charles Charlebois, que le texte risquait de les mettre, lui et ses camarades, « en très mauvaise posture » auprès du délégué apostolique, de Scollard et de « tous nos coreligionnaires irlandais de Sudbury ${ }^{84}$. Le secrétaire de l'ACFÉO, Alexandre Grenon, dut même se porter garant, auprès du délégué, de la "parfaite honorabilité » de Ricard et Hurtubise, qui n'avaient accordé aucune entrevue à La Presse ${ }^{85}$. Le journal montréalais avait forcément puisé à d'autres sources avant de publier l'article, l'affaire de Sudbury ne possédant, somme toute, rien de particulièrement secret.

Si Ricard et Hurtubise avaient souhaité éviter les feux de la rampe, ils n'étaient pas au bout de leurs peines, car le 21 mai, L'Action catholique de Québec reproduisit l'article paru la veille dans La Presse ${ }^{86}$. Pour Scollard, qui s'en plaignit directement

82. J.-Raoul Hurtubise et Félix Ricard, mémoire sur la paroisse Sainte-Annedes-Pins de Sudbury remis à Pietro di Maria, 20 mai 1919, Asv, ANC, 80.10.

83. " Un désaccord entre $\mathrm{M}^{\mathrm{gr}}$ Scollard et les nôtres de la ville de Sudbury », La Presse, 20 mai 1919, CRCCF, FACFO, C2/218/1.

84. Lettre de Félix Ricard à Charles Charlebois, 21 mai 1919, CRCCF, FACFO, $\mathrm{C} 2 / 218 / 1$.

85. Lettre d'Alexandre Grenon à Pietro di Maria, 22 mai 1919, CRCCF, FACFO, $\mathrm{C} 2 / 218 / 1$.

86. « Désaccord entre $\mathrm{M}^{\mathrm{gr}} \mathrm{Scollard}$ et les Canadiens français », L'Action catholique, 21 mai 1919, Asv, ANC, 80.10. 
auprès du cardinal Bégin, c'en était trop. Qu'un journal « sensationnaliste » comme La Presse fît paraître des « half-truths » sur son compte, on ne pouvait guère s'en étonner. Mais qu'un journal comme L'Action catholique, soumis à l'autorité de l'archevêque de Québec, pût se livrer aux mêmes ergotages, occasionner " grave injury to my reputation » et chercher à semer la désunion parmi les catholiques de son diocèse, cela lui paraissait absolument inadmissible ${ }^{87}$. L'évêque de Sault-Sainte-Marie exigea que Bégin intervînt personnellement pour contraindre le rédacteur de L'Action catholique à lui présenter ses excuses. L'archevêque s'en était peut-être mêlé avant même de recevoir la lettre de Scollard, car la veille, L'Action catholique avait publié un second article beaucoup plus sympathique à l'endroit des irlando-catholiques de Sudbury en laissant entendre que l'évêque n'avait peut-être pas donné l'entièreté du terrain de Sainte-Anne aux Canadiens français, tout compte fait ${ }^{88}$. «Avouons que la situation est assez délicate pour Monseigneur », pouvait-on lire en guise de conclusion. La réaction de Scollard à cet article nous est inconnue. Nous savons toutefois qu'à Sudbury, on en fut sidéré. Dans une lettre publiée d'abord dans Le Droit, puis dans Le Devoir, un groupe de paroissiens s'indigna de la publication du texte qui « jet[ait] le blâme [dans cette affaire] sur les Canadiens français » et faisait appel à la paix plutôt qu'à la justice ${ }^{89}$. Or, si la paix était menacée, il fallait en imputer le blâme à Scollard, dont les agissements ne cessaient de jeter de l'huile sur le feu : « [I]l est peu probable que les catholiques des deux langues, qui s'entendront parfaitement s'ils ne sont pas ensemble, vivent dans l'harmonie nécessaire au progrès de la foi et à la prospérité des diverses églises s'ils sont

87. Lettre de David Scollard à Louis-Nazaire Bégin, 27 mai 1919, Asv, ANC, 80.10. Une copie de cette lettre fut envoyée au délégué apostolique : lettre de David Scollard à Pietro di Maria, 27 mai 1919, Asv, Anc, 80.10.

88. « En passant. Au sujet du différend de Sudbury », L'Action catholique, 26 mai 1919, Asv, ANC, 80.10.

89. Des intéressés, Sudbury, Ont., «L'Affaire de Sudbury », Le Devoir, 3 mai 1919, article repris du Droit, 3 mai 1919, Asv, Anc, 80.10. 
aux côtés les uns des autres ${ }^{90} »$. La cohabitation était exclue. Le voisinage aussi.

L'acrimonie avait atteint son comble. En 1919, cependant, le contexte intellectuel était en passe de se transformer. La crise du Règlement 17, qui avait fait des ravages au sein de l'Église canadienne, avait contraint le Saint-Siège à intervenir en publiant deux encycliques sur la question scolaire, l'une en 1916 (Commisso Divinitus), l'autre en 1918 (Litteris Apostolicis), pour tenter de rétablir la concorde entre coreligionnaires irlandais et canadiens-français. Le pape ne remettait pas en cause le droit des Franco-Ontariens de participer au débat politique, mais les mit en garde contre toute action qui eût pu provoquer la majorité angloprotestante à supprimer les écoles séparées de la province, car ce qu'il importait par-dessus tout, souligna-t-il à grands traits, c'était que l'enseignement catholique fût préservé. Ainsi, le souverain pontife donnait raison au parti irlandais en distinguant clairement l'une de l'autre les questions linguistique et religieuse et en rejetant la thèse de la langue, " gardienne » de la foi. Autrement dit, c'était la pierre d'assise du nationalisme canadien-français qui, sous la plume du pape, volait en éclats. L'intervention pontificale sema la consternation parmi les nationalistes, certes, mais elle contribua puissamment, par ailleurs, à la mutation du champ intellectuel canadien-français à partir du tournant des années 1920. En Ontario français, plus précisément, les maquisards des premiers moments de la crise scolaire en viendraient à partager le terrain avec des négociateurs qui croyaient la persuasion et la conciliation plus utiles que la dénonciation et la désobéissance civile ${ }^{91}$. Les modérés, qui parvinrent à infléchir l'action de l'ACFÉO, voulurent, par ailleurs, profiter de l'élan d'ouverture qui avait commencé à se manifester parmi les intellectuels et les politiques du Canada anglais, lesquels cherchaient à réparer les torts infligés à l'unité nationale par la guerre et la crise de la conscription. Ce nouveau

90. Ibid.

91. Nous avons développé ces idées plus longuement dans Michel Bock, « Le Germe d'un divorce : la langue, la foi et le Règlement 17 », op. cit. 
climat intellectuel et politique était peut-être ce qui avait conduit L'Action catholique à se rétracter en publiant une mise au point sur l'affaire de Sudbury. C'était peut-être aussi ce qui fit en sorte que l'AcFÉo en vint à conseiller la modération aux Franco-Sudburois dans la lutte qu'ils livraient à Scollard. Sans aller jusqu'à appuyer le démembrement du terrain de la paroisse Sainte-Anne, l'ACFÉo reconnut la légitimité des inquiétudes des Irlandais, qui cherchaient à éviter que leur nouvelle église fût trop excentrée. Au docteur Hurtubise, 1'Association tenta de faire comprendre que le moment était venu d'abandonner la stratégie de la confrontation et de tendre aux irlando-catholiques une branche d'olivier ${ }^{92}$.

Scollard, toutefois, n'était plus d'humeur à causer. L'accueil qu'il fit à la double intervention pontificale dans la crise qui secouait l'Église canadienne et ontarienne nous est inconnu, bien que nous puissions raisonnablement supposer que cet accueil fut favorable. En mars 1920, il fit parvenir au délégué apostolique la lettre pastorale qu'il s'apprêtait à faire lire aux paroissiens de Sainte-Anne et qui mettrait une fin définitive à la polémique : le terrain de la paroisse serait bel et bien démembré afin d'y ériger la nouvelle église Saint-Joseph ${ }^{93}$. Le prélat nia catégoriquement avoir jamais concédé l'entièreté du terrain aux Canadiens français qui, en voulant tout conserver pour eux, se comportaient de manière déraisonnable. Il fallait toutefois s'attendre, déplora-t-il, à ce que la population franco-catholique de Sudbury vînt de nouveau harceler le délégué apostolique ou encore qu'elle fît parvenir « some more sensational news items to some newspapers », mais l'évêque ne broncherait pas. Scollard avait vu juste, car le docteur Hurtubise revint à la charge auprès de di Maria pour lui faire part de la « consternation » dans laquelle la décision épiscopale avait jeté ses compatriotes ${ }^{94}$. Les paroissiens de Sainte-Anne, réunis

92. Lettre du secrétaire de l'ACFÉo à J.-Raoul Hurtubise, 3 juin 1919, CRCCF, FACFO, C2/218/1.

93. Lettre de David Scollard à Pietro di Maria, 11 mars 1920, Asv, Anc, 80.10. La lettre pastorale que fit parvenir Scollard à di Maria et destinée aux paroissiens de Sainte-Anne est datée du 10 mars 1920.

94. Lettre de J.-Raoul Hurtubise à Pietro di Maria, 14 mars 1920, Asv, ANC, 80.10 . 
en assemblée, lui firent parvenir une ultime protestation «dans l'intérêt de la justice et pour le bien de la religion ${ }^{95}$ », mais le délégué, impassible, se refusa à intervenir. L'évêque avait parlé.

\section{III - L'AFFAIRE DU DROIT}

\section{A. Le déclenchement de la crise (1919)}

L'esprit de modération qui avait gagné une partie de l'élite francoontarienne ne s'était pas nécessairement répandu, toutefois, à tous ses membres. Au Droit, par exemple, l'irréductible père Charlebois n'avait pas encore déposé les armes. Le 22 novembre 1919, il fit publier dans le quotidien ottavien un article pour le moins controversé, lequel équivalait, aux yeux de Scollard, à rien de moins qu'une déclaration de guerre. « La persécution antifrançaise va-t-elle continuer en Ontario ? », demandait le titre avant de dénoncer les « tactiques déplorables dans la nomination des curés dans les paroisses composées en majorité de Canadiens français » dans le diocèse de Sault-Sainte-Marie ${ }^{96}$. Plus précisément, le journal s'inquiétait de la succession de l'abbé Charles Langlois, curé de la paroisse de Sturgeon-Falls, qui venait de trépasser. Le correspondant du Droit s'appliqua à faire le jour sur les intrigues de la minorité irlandaise, laquelle s'ingéniait à persuader l'évêque de Sault-Sainte-Marie de lui nommer un curé de langue anglaise :

Un malaise réel existe dans notre ville d'ordinaire si heureuse et si tranquille. [...] [Les Irlandais désirent rien de plus que de] s'emparer du nid si bien préparé par les labeurs et les sacrifices du Père [sic] Langlois ! Nous comptions bien sur l'esprit de justice et sur le zèle pour le salut des âmes de Monseigneur Scollard, mais l'acharnement qu'il met dans ces derniers temps surtout à recevoir dans le diocèse des sujets de langue anglaise et la répugnance qu'il manifeste à l'admission de prêtres de langue française nous font craindre une nomination désastreuse

95. Lettre d'A. Miron et S. Plouffe, au nom du comité paroissial de SainteAnne-des-Pins, à Pietro di Maria, 2 mai 1920, Asv, ANC, 80.10.

96. «La persécution anti-française va-t-elle continuer en Ontario ? » Le Droit, 22 novembre 1919 , p. 1. 
pour notre paroisse ${ }^{97}$.

La paroisse de Sturgeon-Falls connaîtrait-elle le même sort que celles de Capréol, d'Espanola, de Thessalon, de Coniston, de Copper-Cliff et de Sault-Sainte-Marie, se demanda le correspondant du Droit?

Si la politique de l'élimination graduelle des prêtres de notre langue et de notre mentalité se continue, des soulèvements très regrettables vont se faire. Et la ville de Sturgeon[-]Falls sera la première à vouloir enrayer le mouvement en s'opposant par tous les moyens légitimes à l'arrivée d'un Père [sic] irlandais [...].

Les compatriotes de North[-]Bay se rappellent encore les luttes qu'ils ont dû livrer pour avoir un prêtre qui les comprenne et qui sache conserver chez eux les vieilles et si catholiques traditions paroissiales. Advenant le cas où la politique de l'élimination du clergé de notre langue voudrait poindre, en déplaçant leur curé pour le remplacer par un prêtre irlandais, ils ne seront pas lents à réclamer et à porter leur cause devant qui de droit ${ }^{98}$.

La parution de cet article, qui fut reproduit le jour même dans La Presse de Montréal ${ }^{99}$, eut pour conséquence de dilapider les dernières réserves de patience de Scollard. «Calomnie pure et simple ${ }^{100} », s^{\prime}$ insurgea-t-il dans une lettre pastorale destinée aux fidèles du diocèse. Il n'y avait jamais eu de persécution antifrançaise dans son diocèse, se défendit-il encore, le clergé canadien-français y était le bienvenu au même titre que le clergé irlandais :

Il va sans dire qu'aucun journal catholique digne du nom ne recevrait dans ses colonnes un article aussi diffamatoire et aussi calomnieux. Vous connaissez maintenant, [mes bien chers frères], le tissu de mensonges et d'insinuations malicieuses contenu dans cet article. Comment, par conséquent, pouvezvous croire à la véracité du Droit quand il traite d'autres ques-

97. Ibid.

98. Ibid.

99. «Les Plaintes des nôtres de Sturgeon Falls », La Presse, 22 novembre 1919, article cité dans « Une lettre de $\mathrm{M}^{\mathrm{gr}}$ 1'évêque D.-J. Scollard », La Presse, 27 janvier 1920, CRCCF, FACFO, C2/160/1.

100. Lettre de David Scollard au Droit, 11 décembre 1919, Asv, Anc, 80.11. 
tions dans ses colonnes? Le journal se masque sous le nom de journal catholique afin de répandre plus efficacement au milieu de ses lecteurs l'irrévérence à l'autorité ecclésiastique et afin de fomenter la révolte contre l'évêque du diocèse et de miner la confiance des laïques dans le prêtre. Un tel journal est certainement indigne de l'encouragement des bons catholiques ${ }^{101}$.

Le Droit était-il frappé d'interdiction, désormais, dans le diocèse? La lettre pastorale de l'évêque pouvait bel et bien se prêter à une telle interprétation. À tout le moins, le journal paraîtrait peu recommandable aux yeux de certains fidèles. Après la publication de l'encyclique Litteris Apostolicis, écrivit Scollard au délégué apostolique di Maria, le geste du Droit représentait un affront injustifiable ${ }^{102}$. L'évêque avait d'ailleurs consulté ses avocats et menaçait de porter sa cause devant les tribunaux civils pour obtenir quelque réparation, à moins que le journal ne fît paraître une rétractation et des excuses formelles ${ }^{103}$. Di Maria, qui cherchait d'abord et avant tout à éviter le scandale qu'aurait représenté une poursuite intentée par un évêque contre un journal catholique, tenta bien de l'en dissuader. Scollard, qui ne négligeait aucun moyen d'action, s'adressa aussi à l'archevêque d'Ottawa, Charles Hugh Gauthier : "Now, I call upon Your Grace to use that authority given you by the Holy Ghost to compel Le Droit to make reparation to me for that defamatory article ${ }^{104}$. » Scollard exigeait que fussent publiés dans le journal non seulement sa propre lettre pastorale, mais aussi un texte d'excuses qu'il avait lui-même pris le soin de rédiger. Le 25 décembre, le délégué apostolique reçut chez lui le rédacteur du Droit, Albert Foisy, lequel aurait acquiescé à la demande du prélat ${ }^{105}$. Foisy se précipita toutefois à l'hôtel de

101. Ibid. 80.11 .

102. Lettre de David Scollard à Pietro di Maria, 16 décembre 1919, Asv, ANC,

103. Lettre de David Scollard à Pietro di Maria, 22 décembre 1919, Asv, Anc, 80.11 .

104. Lettre de David Scollard à Charles Hugh Gauthier, 19 décembre 1919, CRCCF, FACFO, C2/160/1.

105. Lettre de Pietro di Maria à David Scollard, 31 décembre 1919, Asv, ANC, 80.11 . 
ville où il déclara sous serment que, pendant l'entretien, di Maria avait soutenu, à l'encontre de Scollard, que Le Droit était « tout imprégné de catholicisme », et que c'était pour cette raison que les choses rentreraient bientôt dans l'ordre $^{106}$. Visiblement, le journal avait été ébranlé par les accusations de l'évêque de Sault-SainteMarie et cherchait à éviter à tout prix qu'on pût se méprendre sur son dévouement à la cause catholique.

Le texte d'excuses, toutefois, tardait à paraître. Scollard mit donc sa menace à exécution en expédiant une mise en demeure au propriétaire du Droit, le Syndicat d'œuvres sociales, le seul moyen, à son avis, de le faire agir ${ }^{107}$. Il ne s'était pas totalement trompé, car quelques jours plus tard parut une courte « Explication » qui citait quelques brefs extraits de sa lettre pastorale, sans toutefois inclure les passages les plus désobligeants envers le journal et sans non plus lui présenter les excuses qu'il réclamait ${ }^{108}$. Exaspéré, Scollard exhorta Gauthier et di Maria à confronter le père Charlebois, le délégué apostolique l'implorant, en retour, de mettre fin à ses démarches judicaires ${ }^{109}$. "The scandal would be enormous », s'inquiéta-t-il, et ne manquerait pas de lui attirer les foudres du Saint-Siège ${ }^{110}$. Il importait par-dessus tout, estimait di Maria, que cette affaire fût réglée à l'intérieur même de l'Église, quitte à remonter jusqu'à Rome, si les autres recours s'avéraient infructueux. Le Droit, du reste, partageait le même avis : seul un tribunal ecclésiastique était compétent pour trancher l'affaire, car « un procès civil dans une telle question aurait été souverainement malheureux pour l'Église catholique à laquelle les deux parties en

106. Déclaration sous serment d'Albert Foisy, 30 décembre 1919, CRCCF, FACFO, C2/160/1.

107. Mise en demeure envoyée par David Scollard, par l'entremise de maître M. Gorman, au Syndicat d'œuvres sociales, 2 janvier 1920, CRCCF, FACFO, C2/160/1 ; lettre de David Scollard à Pietro di Maria, 3 janvier 1920, Asv, ANc, 80.11.

108. «Explication », Le Droit, 10 janvier 1920, p. 1.

109. Lettres de David Scollard à Pietro di Maria, 14 janvier 1920 ; Pietro di Maria à Charles Hugh Gauthier, 19 janvier 1920 ; de Pietro di Maria à David Scollard, 19 janvier 1920, Asv, ANC, 80.11. 80.11

110. Lettre de Pietro di Maria à David Scollard, 21 janvier 1920, Asv, ANC, 
cause [étaient] sincèrement attachées ${ }^{111} \gg$. Scollard ne décolérait pas, pourtant, et réitéra sa volonté de régler l'affaire devant les tribunaux, sa réputation ayant été gravement atteinte ${ }^{112}$. Il accepta toutefois que di Maria se fît arbitre et s'engagea à se conformer à son verdict, pour peu que Le Droit en fît autant. Il souhaitait aussi que l'archevêque Gauthier fût écarté du processus, car l' « Explication » qu'avait publiée le journal était vraisemblablement son œuvre. Il avait tort, car Gauthier avait bel et bien tenté de faire publier une rétractation et des excuses complètes par Le Droit, qui

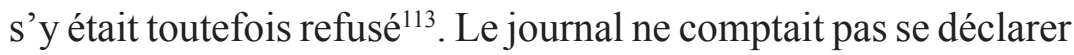
vaincu de sitôt. « Nous ne croyons pas qu'il [notre journal] doive s'exécuter lui-même en publiant des expressions telles que celles contenues dans votre lettre », lança-t-il à Scollard en déplorant que l'évêque se montrât plus sévère envers lui qu'envers la presse protestante qui, pendant la guerre, s'était amusée à présenter le pape comme l'ami des Allemands ${ }^{114}$ !

L'amertume et l'antipathie mutuelles que s'inspiraient les deux partis ne donnaient aucun indice de modération. S'ensuivit alors un véritable tourbillon de correspondances, d'articles et de délégations entre les principaux acteurs de ce drame. Il y allait de l'intérêt de la foi et de l'Église que l'affaire tombât dans l'oubli, soutenait Le Droit, et qu'on évitât à tout prix « le scandale d'un procès civil ${ }^{115}$. « The spirit of race hatred » qui s'était emparé du Droit, rétorqua Scollard, lui avait fait perdre la raison et l'empêchait de rendre justice à un prélat qui avait le malheur de ne pas être canadien-français ${ }^{116}$. De surenchère en surenchère, le

111. Le Syndicat d'œuvres sociales à M.J. Gorman, 12 janvier 1920, CRCCF, FACFO, C2/160/1. 80.11 .

112. Lettre de David Scollard à Pietro di Maria, 22 janvier 1920, Asv, AnC,

113. "Projet d'explication plus complète ", [?] janvier 1923, CRCCF, FACFO, C2/160/1; lettre du Syndicat d'œuvres sociales à Charles Hugh Gauthier, 23 janvier 1920, CRCCF, FACFO, C2/160/1.

114. Lettre du Droit à David Scollard, 20 janvier 1920, CRCCF, FACFO, C2/160/2.

115. Lettres du Droit à David Scollard, 16 et 20 janvier 1920, CRCCF, FACFO, C2/160/1. 80.11 .

116. Lettre de David Scollard à Pietro di Maria, 30 janvier 1920, Asv, AnC, 
terrain d'entente se rétrécissait comme une peau de chagrin. Puis, le 27 janvier, La Presse, qui avait reproduit l'article initial du Droit au moment même du déclenchement de la crise, fit paraître sa propre rétractation accompagnée d'une lettre de Scollard qui se défendait d'avoir « persécuté » ses prêtres canadiens-français : « Nous sommes bien heureux de publier ces explications de $M^{\text {gr }}$ l'évêque de Sault-Sainte-Marie et nous regrettons que par suite de ce que nous croyons être un malentendu on ait douté, pendant quelque temps, des bonnes dispositions de $\mathrm{M}^{\text {gr }}$ Scollard à l'endroit de son clergé d'origine canadienne-française ${ }^{117}$. » Le dévouement de La Presse à la cause catholique n'était pourtant pas supérieur à celui du Droit. Si le grand quotidien libéral de Montréal avait senti la nécessité de montrer patte blanche au prélat, le journal oblat d'Ottawa réussirait-il à tenir le coup pendant encore très longtemps ?

La presse, faut-il le préciser, faisait ses choux gras de l'affaire du Droit et grand cas de l'éventuelle poursuite qui continuait de planer au-dessus de sa tête comme une épée de Damoclès. L'on sentait bien que le vent avait tourné et que l'appel à la modération lancé par le pape, moins de deux ans plus tôt, commençait à se faire entendre. À Québec, le journal L'Événement se lança dans la mêlée en morigénant Le Droit qui voulait « se faire passer pour catholique afin de mieux colporter son poison nationaliste ${ }^{118} »$ :

Il n'y a pas très longtemps, le Souverain Pontife a envoyé aux catholiques canadiens une lettre comportant des instructions et des avis sévères au sujet des relations entre catholiques de langue française et de langue anglaise. Cela n'a pas empêché le « Droit » d'accuser faussement un évêque catholique de persécuter la langue française et les prêtres canadiens-français dans son diocèse.

Le journal soi-disant catholique mais très notoirement nationaliste d'Ottawa est mis en demeure aujourd'hui par l'évêque du Sault-Sainte-Marie, S.G. M ${ }^{\text {gr }}$ Scollard, de répondre devant les cours de justice de ses accusations mensongères. Il a été

117. «Une lettre de $\mathrm{M}^{\mathrm{gr}}$ l'évêque D.-J. Scollard », La Presse, 27 janvier 1920, CrCCF, FaCfo, C2/160/1.

118. «Un exemple », L’Événement, 28 janvier 1920, CRCCF, FACFO, C2/160/1. 
dénoncé dans une lettre publique par le chef d'un diocèse qui recommande à ses fidèles de ne point souscrire à un journal qui attaque et calomnie publiquement un évêque catholique. [...]

Sa conduite à l'égard d'un évêque catholique, venant si peu de temps après les avis sévères du Saint-Siège sur les relations entre catholique canadiens, trahit le défaut de discipline catholique chez les sectaires nationalistes d'Ottawa. Son nationalisme va-t-il jusqu'à réclamer l'indépendance absolue des catholiques canadiens-français ${ }^{119}$ ?

L'article de L'Événement n'était pas exempt d'hyperbole, mais il n'en fit pas moins au Droit l'effet d'une giffe. Le journal commençait à prendre la pleine mesure de l'embarras dans lequel il se trouvait et comprit qu'il était allé au bout de son effort de résistance, d'autant plus qu'à Sturgeon-Falls, Scollard avait nommé un prêtre canadien-français, l'abbé J.A. Lécuyer, pour succéder au curé Langlois... Ainsi, il accepta que le délégué apostolique jouât les médiateurs dans son différend avec l'évêque et promit, à son tour, de se conformer à son jugement ${ }^{120}$. Les deux partis s'accusèrent mutuellement de tergiverser, Scollard refusant de retirer la mise en demeure qu'il avait faite au journal tant et aussi longtemps que l'affaire ne serait pas réglée, mais ils convinrent enfin de se réunir en présence du délégué et de l'archevêque d'Ottawa le 17 février $^{121}$. Le Droit, épuisé et défait, se déclara vaincu. Trois jours plus tard, la lettre pastorale de Scollard fut publiée dans le journal, de même que la rétractation qu'il avait réclamée à cor et à cri : « Nous regrettons que [l'article initial] ait échappé au véritable contrôle et puisque S.G. M $^{\text {gr }}$ Scollard affirme que notre correspondant nous a mal renseigné[s], nous lui devons réparation pour le tort que son autorité épiscopale a pu en éprouver. Nous nous acquittons de ce devoir et nous reconnaissons, comme tout

119. Ibid.

120. Lettres du Syndicat d'œuvres sociales à David Scollard, $1^{\text {er }}$ et 3 février 1920 ; de David Scollard au Syndicat d'œuvres sociales, 2 février 1920, CRCCF, FACFO, C2/160/1 ; de David Scollard à Pietro di Maria, 6 février 1920, Asv, Anc, 80.11.

121. Lettres de David Scollard au Syndicat d'œuvres sociales, 11 février 1920 ; du Syndicat d'œuvres sociales à David Scollard, 12 février 1920, CRCCF, FACFO, C2/160/1 ; de Pietro di Maria à David Scollard, 11 février 1920 ; de David Scollard à Pietro di Maria, 12 février 1920, Asv, ANC, 80.11. 
journal catholique doit le faire, que les actes épiscopaux relèvent directement du Saint-Siège ${ }^{122}$. » L'Événement, qui continuait de suivre avidement la polémique, dissimula mal sa satisfaction. Le lendemain, il se réjouit du « retour de notre confrère dans la bonne voie », tout en tirant de cette affaire une « leçon profitable» :

Il faut se garder de l'outrance, surtout en ce qui a trait au respect dû aux autorités ecclésiastiques. Lorsque les catholiques d'un pays ont le malheur d'être divisés sur une question politique et nationale, on doit confier le soin de diriger sa cause à des hommes sages et prudents, qui, par leurs paroles, leurs écrits ou leurs actes, ne compromettront jamais leur cause et leur patrie.

Dans l'Ontario, le conflit bilingue a faussé bien des jugements. Les exagérations d'un certain clan ont fait autant de tort aux Canadiens français que la persécution réelle qu'ils ont à subir. Le mauvais exemple du « Droit », s'attaquant violemment à un évêque catholique au sujet de l'administration de son diocèse et laissant s'écouler près de trois mois avant de reconnaître sa faute, devrait être salutaire. Cet accès de fanatisme étant d'autant moins pardonnable qu'il se produisait relativement peu de temps après les instructions de Rome sur la conduite à suivre pour améliorer une situation trop tendue entre les catholiques du Canada ${ }^{123}$.

\section{B. Accalmie ou guerre froide ? Le dénouement de la crise et ses suites (1920-1934)}

On ne dira jamais assez combien l'intervention de Rome dans la crise scolaire franco-ontarienne a pesé lourd dans la mutation du contexte intellectuel du Canada français pendant les années 1920. Le Droit venait de comprendre qu'il devrait, dorénavant, apprendre à peser ses mots lorsque l'autorité épiscopale était en jeu. Il était néanmoins parvenu à obtenir, à l'arraché, une concession importante de la part de l'évêque qui, en plus d'abandonner ses menaces de poursuite judiciaire, s'était engagé à lever l'interdiction qui pesait encore sur le journal à Sault-Sainte-Marie et à publier un mandement qui en recommanderait la lecture. Or, un mois après la parution de la rétractation, le mandement

122. «Réparation », Le Droit, 20 février 1920, CRCCF, FACFO, C2/160/1.

123. «Réparation », L'Événement, 21 février 1920, CRCCF, FACFO, C2/160/1. 
n'avait toujours pas circulé ${ }^{124}$. Les dirigeants du journal avaient convoqué toute leur volonté pour donner satisfaction à l'évêque et voici qu'il ne semblait pas vouloir tenir parole. Scollard attendit encore deux mois avant de leur répondre laconiquement qu'il avait déjà indiqué à plusieurs de ses prêtres qu'il n'avait plus d'objection à ce que Le Droit fût lu dans le diocèse. «No doubt they have communicated this withdrawal to their people ${ }^{125} »$, se borna-t-il à préciser. Le père Charlebois, toujours sur ses gardes lorsqu'il s'agissait du clergé irlandais, fit sa petite enquête auprès de quelques prêtres du diocèse, dont l'abbé Racette, de Verner, qui lui dit n'avoir encore rien reçu de la part du prélat (lequel n'avait pas non plus daigné participer aux festivités entourant le $25^{\mathrm{e}}$ anniversaire de sa paroisse, ajouta-t-il avec une pointe d'indignation $)^{126}$. D'autres confirmèrent toutefois les dires de Scollard, dont le curé de Chelmsford, Stéphane Côté, qui avait reçu de son évêque une carte postale sur laquelle il était écrit la phrase suivante : "As long as Le Droit keeps the little corner into which I pushed it and leaves bishops and the administration of their diocese alone, priests and people may read it ${ }^{127}$ "). L'appui était loin d'être retentissant. Il était clair que l'évêque n'avait entrepris aucune démarche systématique ou formelle pour réhabiliter Le Droit dans son diocèse, alors qu'il avait pris le soin, en revanche, de redistribuer, « au grand étonnement de tous », son mandement du 11 décembre 1919 le condamnant ${ }^{128}$. Le Syndicat d'œuvres sociales exigea qu'il respectât sa promesse, déjà vieille de cinq mois, et qu'il fît circuler un nouveau mandement recommandant, cette fois, la lecture du Droit. Mais Scollard s'obstinait. S'il n'avait pas fait montre d'un plus grand zèle au moment de

124. Lettre du Droit à David Scollard, 18 mars 1930, CRCCF, FACFO, C2/160/1.

125. Lettre de David Scollard au Droit, 25 mai 1920, CRCCF, FACFO, C2/160/1.

126. Lettres de Charles Charlebois à Oscar Racette, 6 juillet 1920 ; d'Oscar Racette à Charles Charlebois, 10 juillet 1920, CRCCF, FACFO, C2/160/1.

127. Lettre de Stéphane Côté à Charles Charlebois, 16 août 1920, CRCCF, FACFO, $\mathrm{C} 2 / 160 / 1$.

128. Lettres de M. Lécuyer à Charles Charlebois, 20 juillet 1920, CRCCF, FACFO, C2/160/1; du Droit à David Scollard, 20 juillet 1920, Asv, ANC, 80.11. 
remplir les conditions de l'entente, rétorqua-t-il, c'est que sa lettre condamnant le journal avait été lue « in such a low and subdued tone of voice » à l'église Sainte-Anne de Sudbury, que peu de gens avaient pu prendre connaissance de son contenu ${ }^{129}$. En réalité, il ne s'agissait là que d'un prétexte, car Scollard révéla au délégué apostolique qu'il se refusait à publier le mandement promis tant et aussi longtemps que la direction du Droit serait assurée par le père Charlebois, qui se livrait à de «malicious secret plottings [...] to defame my character before Your Excellency ${ }^{130} »$. Di Maria prit note de l'accusation, sans plus ${ }^{131}$. La victoire de l'évêque de Sault-Sainte-Marie était totale.

L'affaire du Droit avait grandement contribué à calmer l'ardeur belliqueuse de l'élite nationaliste de l'Ontario français. Désormais, la prudence serait de mise. À l'ACFÉo, le retour à la présidence de l'avocat et sénateur libéral Napoléon-Antoine Belcourt marqua l'adoption d'une nouvelle stratégie dans le combat contre le Règlement 17, une stratégie faisant une part beaucoup plus grande à la conciliation. Dans le diocèse de SaultSainte-Marie, aussi, les coups d'éclat se feraient plus rares. Non que la situation linguistique eût été au beau fixe, bien au contraire, car on se plaignait encore régulièrement de la rareté des prêtres canadiens-français, entre autres choses. Seulement, l'expression de ces plaintes se faisait maintenant plus discrètement et, surtout, sans que Scollard et le clergé irlandais fussent publiquement pointés du doigt ${ }^{132}$. La polémique la plus substantielle à survenir pendant cette période fut déclenchée en 1924, à North-Bay, lorsque l'évêque fit acheter par la corporation épiscopale un terrain destiné à la construction d'une nouvelle école, contournant ainsi les prérogatives de la commission scolaire séparée dont il

129. Lettre de David Scollard au Droit, 14 août 1920, CrCCF, FACFO, C2/85/8.

130. Lettre de David Scollard à Pietro di Maria, 3 mars 1921, Asv, Anc, 80.11.

131. Lettre de Pietro di Maria à David Scollard, 21 mars 1921, Asv, ANC, 80.11.

132. Lettre de H. Gauthier à [ ?], 15 octobre 1922, CRCCF, FACFO, C2/15/6 ; résolution adoptée au congrès régional du Nouvel-Ontario de l'ACFÉO, CRCCF, FACFO, C2/15/8 ; rapport présenté par J.-Raoul Hurtubise au congrès général de l'ACFÉO, 17 avril 1928, CRCCF, FACFO, C2/7/14. 
était pourtant le secrétaire-trésorier. Le problème fut porté à la connaissance de l'AcFÉo par Wilfrid Aubry, l'un de ceux que Scollard avait semoncés du haut de sa chaire en 1908, au moment de la célèbre affaire de la chorale. Le prélat avait affirmé, selon Aubry, que le sens de sa démarche était de lui donner l'autorité nécessaire à la fermeture de l'école dans l'éventualité où il serait insatisfait des instituteurs embauchés par la commission. « [A]lors vous pouvez voir le danger, pour nous Canadiens français, qu'il y a quand nous serons à la merci du clergé irlandais ${ }^{133}$. » Même le président de l'AcFÉo, le très modéré Napoléon Belcourt, à qui Aubry avait demandé conseil, partageait son avis : la conduite de Scollard était « irrégulière », « condamnable » et contraire à la loi scolaire de l'Ontario. Le temps était venu de « mettre fin à son ingérence et à sa domination dans les choses qui ne tomb[ai]ent pas sous la juridiction épiscopale ${ }^{134} \gg$. Serait-il nécessaire de faire appel aux tribunaux ? Aubry, qui connaissait bien l'irascibilité de son évêque pour en avoir jadis fait les frais, voulut régler l'affaire « avant que [ne] surgissent des événements regrettables et peutêtre scandaleux ${ }^{135} »$. C'est pourquoi il tenta de rallier à sa cause le délégué apostolique et même... le pape ${ }^{136}$ ! La suite de cette histoire demeure nébuleuse. L'école fut construite, mais éventuellement transférée de la corporation épiscopale à la commission scolaire, Scollard abandonnant, de surcroît, non seulement le droit de regard qu'il avait voulu se donner sur l'embauche des instituteurs, mais aussi le poste de secrétaire-trésorier de la commission scolaire ${ }^{137}$. Les raisons l'ayant motivé à agir de la sorte nous sont inconnues, bien que Wilfrid Aubry y vît le résultat de

133. Lettre de Wilfrid Auby à Napoléon-Antoine Belcourt, 20 juin 1924, CRCCF, FACFO, C2/160/3.

134. Lettre de Napoléon-Antoine Belcourt à Wilfrid Aubry, 30 juin 1924, CRCCF, FACFO, C2/160/3.

135. Lettres de Wilfrid Aubry à Pietro di Maria, 2 septembre 1924, CRCCF, FACFO, $\mathrm{C} 2 / 160 / 3$.

136. Lettres de Wilfrid Aubry à Pietro di Maria, 2 septembre 1924 ; à Pie XI, 3 septembre 1924, CRCCF, FACFO, C2/160/3.

137. Lettres de Wilfrid Aubry à Edmond Cloutier, 21 novembre 1925 ; à l'éditeur du Droit, 23 janvier 1926, CRCCF, FACFO, C2/160/3. 
la « résistance » qu'il avait su organiser.

Il est possible que l'élite canadienne-française n'ait pas été la seule à avoir entendu l'appel au calme du pape. Sur la place publique, à tout le moins, Scollard faisait bel et bien montre d'une plus grande retenue dans ses rapports avec la population franco-catholique. Dans les coulisses, toutefois, il semblait toujours s'inquiéter des « intrigues » des Canadiens français dont, au premier chef, celles du Droit, qui complotait, selon un de ses correspondants, pour obtenir la promotion au rang de ministre du député fédéral de Nipissing, E.A. Lapierre, et pour faire nommer un second Franco-Ontarien au Sénat ${ }^{138}$. Scollard tenta aussi d'obtenir la nomination d'un juge anglo-catholique dans le Nouvel-Ontario, prétextant l'injustice que représentait le fait que les Franco-Ontariens, qui, de toute manière, s'anglicisaient rapidement, en avaient déjà deux ${ }^{139}$. Malgré tout, la trêve des années 1920 semblait vouloir tenir, sans toutefois que l'on pût parler de réconciliation dans le plein sens du mot. Le discours que prononça, en 1930, le juge J.A.S Plouffe de Sudbury lors du banquet organisé pour célébrer les noces d'argent épiscopales de Scollard est hautement révélateur de l'ambiguité qui caractérisait ses rapports avec les franco-catholiques de son diocèse. Se réjouissant à la vue de tous ceux qui s'étaient déplacés pour rendre hommage à « notre père commun ", Plouffe souhaita longue vie à l'évêque, ainsi qu'à son « incomparable clergé qui a[vait] été plus particulièrement témoin de [sa] bonté et de [sa] toute paternelle sollicitude », et enchaîna en espérant que son règne se prolongeât « pour qu'il [fût] aussi fructueux à l'avenir qu'il l'a[vait] été dans le passé $»^{140}$. L'orateur, cependant, ne se bornerait pas à faire l'éloge du prélat, éloge dans lequel il est d'ailleurs tentant de constater une forte

138. Lettre de « L.B. » à David Scollard, 15 décembre 1926, CRCCF, FACFO, C2/160/6. Le docteur Gustave Lacasse, de Windsor, serait nommé au Sénat par Mackenzie King deux ans plus tard.

139. Lettre de David Scollard à Hugh Guthrie, 4 juin 1934, CRCCF, FACFO, C2/160/6.

140. J.A.S. Plouffe, discours prononcé lors du banquet diocésain organisé pour célébrer les noces d'argent épiscopales de Scollard, 7 mai 1930, CRCCF, FACFO, C2/159/23. 
pointe d'ironie. Se faisant le représentant du « groupement ethnique le plus considérable que la divine Providence » eût placé dans le diocèse, Plouffe proclama haut et fort que la langue, pour les Canadiens français, demeurait le «bouclier de la foi », vérité dont toute l'histoire du Canada fournissait la preuve :

[Héritiers de la mission apostolique de France,] nous avons poursuivi sur le continent américain le même idéal que nos pères s'étaient proposé dans le vieux monde. Chaque page de notre glorieuse histoire atteste notre catholicisme. Les pionniers de ce pays cherchèrent à y établir le règne du Christ d'abord, puis ils léguèrent cette noble ambition à leurs enfants, qui portèrent d'un bout à l'autre de ce continent l'étincelle de leur civilisation et les lumières de notre sainte foi. Qu'il suffise d'énumérer ici les noms des Cartier, des Champlain, des Maisonneuve, des de Laval, des Laflèche, des Langevin, des bienheureux martyrs jésuites, de se rappeler les hauts faits de tous ces hommes illustres pour affirmer que la mission de la race française, là où elle se trouve, en Amérique comme en Europe, est de continuer les « Gesta dei per Francs » ${ }^{141}$.

L'abbé Groulx aurait à peine mieux dit. Personne ne dut se méprendre sur le véritable sens du discours de Plouffe : chercher à étouffer la présence française en Ontario était un affront au catholicisme, l'histoire et le destin du Canada français étant inséparables de ceux de l'Église en Amérique. Le pied de nez qu'il lança à la figure de Scollard était à peine voilé :

C'est pour conserver notre catholicisme dans toute son intégrité que nous avons lutté avec tant d'acharnement et de persévérance depuis une quinzaine d'années contre ceux qui cherchaient obstinément à bannir le français de nos écoles. La Providence a béni nos efforts, nous l'en remercions à genoux. Nous nous réjouissons avec vous, Monseigneur, du commencement de victoire que nous avons obtenue [avec la fin de la crise scolaire en 1927].

[...] La langue d'un peuple est toujours un lien sacré, mais quand cette langue s'appelle la langue française, quand elle a l'honneur de porter comme dans un écrin le trésor de la pensée humaine enrichi de toutes les traditions des grands siècles 
catholiques, la mutiler serait un crime, la mépriser, la négliger même, une apostasie ${ }^{142}$.

De phrase en phrase, la critique se transformait en mise en garde : «Aussi, Monseigneur, nous nous proposons dans l'intérêt même de l'Église en cette province et en notre cher diocèse, de veiller jalousement sur la conservation de ce précieux héritage, que nous voulons transmettre à nos enfants comme nous l'avons reçu de nos pères pour la plus grande gloire de Dieu ${ }^{143}$. » Il y avait une bonne part de provocation dans cet « hommage » de Plouffe à Scollard, dont les liens d'amitié avec les Canadiens français du diocèse de Sault-Sainte-Marie et d'ailleurs avaient toujours été pour le moins ténus... Malgré l'apaisement des dernières années, la population franco-catholique n'avait pas encore passé l'éponge sur les torts qu'elle continuait de lui reprocher.

Trois ans plus tard, le bruit se mit à courir que Scollard, dont la santé dépérissait, avait commencé à songer à sa succession et à se chercher un coadjuteur. Le jeune sénateur Gustave Lacasse, d'Essex, fut parmi les premiers à exprimer ses inquiétudes au délégué apostolique, Andrea Cassulo : «L'on craint fort que le choix, inspiré sans doute par S. Exc. M ${ }^{\text {gr }}$ Scollard lui-même, ne tombe sur une personne de langue anglaise - ou du moins de mentalité anglaise ${ }^{144}$. » Lacasse mobilisa les mêmes arguments qui avaient servi, en 1908 et en 1913, à réclamer sa mutation à Toronto, à London et à Peterborough, car la grande majorité des catholiques du diocèse de Sault-Sainte-Marie était, encore et toujours, de langue française. Le règne de Scollard avait provoqué, par ailleurs, des « acrimonies regrettables » que seule la nomination d'un évêque canadien-français pouvait dissiper. Le docteur Hurtubise, qui représentait le comté de Nipissing à la Chambre des communes depuis 1930, entreprit lui aussi plusieurs démarches auprès de Cassulo pour tenter d'obtenir que le suc-

142. Ibid.

143. Ibid.

144. Lettre de Gustave Lacasse à Andrea Cassulo, 15 mars 1933, CRCCF, FACFO, C2/153/10. 
cesseur de Scollard fût canadien-français ${ }^{145}$. Aucun coadjuteur ne fut choisi, toutefois, avant que l'évêque de Sault-Sainte-Marie ne s'éteignît le 7 août 1934, à North-Bay. L'heure était grave, car l'avenir du diocèse se jouerait sans doute rapidement. Hurtubise revint à la charge auprès du délégué apostolique en lui expédiant une longue lettre détaillant les progrès démographiques, institutionnels et économiques de la population canadienne-française qui était la force vive du catholicisme dans le diocèse ${ }^{146}$. L'Ordre de Jacques-Cartier somma d'ailleurs le député de plaider sa cause devant le délégué du Canada au Saint-Siège pour faire cesser l' « injustice » qui régnait depuis trop longtemps à Sault-SainteMarie $^{147}$. Hurtubise obtint aussi l'appui, entre autres, du sénateur Rodolphe Lemieux et de l'ambassadeur de France au Vatican ${ }^{148}$.

La décision du Saint-Siège tomba comme un couperet le 22 décembre. Le diocèse ne serait pas gouverné par un évêque canadien-français. Pire encore, le candidat retenu pour succéder à Scollard était Ralph Hubert Dignan, un prêtre du diocèse de London, le fief de feu Michael Fallon, que devançait sa réputation en matière linguistique et nationale... Hurtubise ne put contenir sa déception. La hiérarchie avait laissé tombé, une fois de plus, les Franco-Ontariens de Sault-Sainte-Marie :

[P] ermettez-moi, Excellence [Andrea Cassulo], de vous exprimer respectueusement le regret du groupe canadien-français de notre diocèse de voir leurs désirs relégués à l'arrière-plan. Ils sont convaincus qu'ils ont contribué par leur nombre, par leur travail et par leur influence au développement des œuvres catholiques dans cette région et, comptant sur cette force, leur désir et leur ambition eussent été d'avoir comme premier pasteur de ce diocèse un évêque de leur mentalité, afin de compléter le travail si bien commencé dans la colonisation,

145. Lettre de J.-Raoul Hurtubise à Andrea Cassulo, 20 juin 1934, CRCCF, FACFO, C2/153/10.

146. Lettre de J.-Raoul Hurtubise à Andrea Cassulo, 18 septembre 1934, CRCCF, FACFO, C2/153/10.

147. Lettre des Commandeurs de l'Ordre de Jacques-Cartier à J.-Raoul Hurtubise, 27 septembre 1934, CRCCF, FACFO, C2/194/2.

148. Robert Choquette, La Foi, gardienne de la langue en Ontario, op. cit., p. 65. 
la création de nouvelles paroisses et la fondation de nouvelles maisons d'éducation ${ }^{149}$.

Hurtubise espérait, à tout le moins, que le délégué apostolique se ferait l' « interprète » des Canadiens français auprès du nouvel évêque, mais le sentiment d'abattement était palpable. Le règne de Dignan, « vrai disciple de Fallon ${ }^{150}$ », selon Robert Choquette, était promis, lui aussi, à la controverse.

L'histoire de l'épiscopat de David Scollard dans le diocèse de Sault-Sainte-Marie prend parfois les allures d'un feuilleton. Le personnage, comme ses adversaires, était coloré et traversa avec eux une série de rebondissements tantôt dramatiques, tantôt cocasses. Au-delà de la mise en scène des personnalités qui ont peuplé ce récit, cependant, l'historien peut dégager un certain nombre de conclusions. La première concerne le rapport de force entre Scollard et ses ouailles canadiennes-françaises. Ce rapport était inégal, certes, mais la puissance démographique des franco-catholiques dans le diocèse leur accordait tout de même un certain poids. Ainsi, bien qu'il eût appuyé les politiques scolaires du gouvernement provincial, il pouvait difficilement en imposer le respect dans l'ensemble des écoles séparées de son diocèse. En certains endroits, comme à Sudbury, on agissait simplement « comme si le Règlement [17] n'existait pas ${ }^{151}$ ». Ses méthodes pour contenir l'influence canadienne-française, d'ordinaire plus subtiles, consistaient plutôt à renforcer le clergé irlandais et à faire de l'anglais, dans la mesure du possible, la langue « publique » de l'Église diocésaine. Le père Charlebois, en décrivant la logique des agissements de l'évêque au délégué Stagni, employa

149. Lettre de J.-Raoul Hurtubise à Andrea Cassulo, 4 janvier 1935, CRCCF, FACFO, C2/153/10. p. 66.

150. Robert Choquette, La Foi gardienne de la langue en Ontario, op. cit.,

151. Jacques Taillefer, «L'AcFÉo à Sudbury, 1910-1927 », op. cit., p. 40. Voir Victor Simon, Le Règlement XVII. Sa mise en vigueur à travers l'Ontario 1912-1927, Sudbury, Société historique du Nouvel-Ontario, coll. " Documents historiques », $\mathrm{n}^{\circ} 78,1983$, p. 58. 
des termes similaires : « [Sa Grandeur] a avoué publiquement [...] que le français devrait être parlé dans la famille mais qu'en public, dans les assemblées, etc., la langue anglaise devrait être parlée ${ }^{152}$. » Bien entendu, cette façon de concevoir la langue française ne le conduisait pas à favoriser l'autonomie institutionnelle (paroissiale, en l'occurrence) des fidèles canadiens-français, sauf lorsqu'il y était contraint par des nécessités irrépressibles. Malgré les frasques qu'il pouvait commettre à l'occasion, il eût été difficile pour lui de sévir à Sault-Sainte-Marie comme le faisait Fallon à London.

De manière plus générale, toutefois, cette étude a permis de mieux apercevoir les éléments qui ont contribué à la mutation du champ intellectuel canadien-français pendant les années 1920. La double intervention pontificale dans la crise du Règlement 17 en 1916 et en 1918 eut pour effet de créer une véritable onde de choc dans les milieux intellectuels de tout le Canada français, phénomène que l'historiographie n'a cependant pas évalué à sa juste mesure ${ }^{153}$. La thèse de la langue, "gardienne » de la foi, c'est-à-dire, en termes plus prosaïques, celle de l'union des questions nationale et religieuse, fut rejetée sans ambages, d'abord par le délégué apostolique Stagni, qui condamna vertement le « nationalisme excessif ${ }^{154}$ » du père Charlebois et de ses acolytes, puis par le Saint-Siège lui-même. La question religieuse n'était pas, aux yeux de la hiérarchie, une question politique (ou « nationale »), voilà qui était clair. L'intervention de Rome dans la crise franco-ontarienne initia une profonde remise en question des fondements mêmes du nationalisme canadien-français « orthodoxe » que viendraient exacerber, pendant les années 1920, plusieurs autres prises de position pontificales et épiscopales. Pensons à

152. Lettre de Charles Charlebois à Pellegrino Stagni, avril 1913, CRCCF, FACFO, C2/153/10.

153. Michel Bock, « Le Germe d'un divorce : la langue, la foi et le Règlement $17 »$, op. cit.

154. Pour une traduction anglaise des rapports de Stagni sur la question scolaire ontarienne, voir John Zucchi, The View from Rome. Archbishop Stagni's 1915 Reports on the Ontario Bilingual Schools Question, Montréal et Kingston, McGill-Queen's University Press, 2002, 131 p. L'extrait concernant Charlebois se trouve à la p. xlvii. 
la condamnation, en 1922, du « nationalisme immodéré », qui acheva de convaincre Henri Bourassa, notamment, de tourner le dos à ses convictions nationalistes antérieures. Pensons encore à la condamnation, quatre ans plus tard, du « nationalisme outrancier » de L'Action française de Paris, laquelle causa de graves ennuis à la revue homonyme de Montréal, dont l'élite franco-ontarienne comptait parmi les plus fidèles lecteurs et collaborateurs. L'Action française de Lionel Groulx, qui n'avait jamais subordonné son catholicisme à son nationalisme, avait beau ne pas être coupable des mêmes erreurs que le journal de Charles Maurras, les mauvaises langues avaient déjà commencé à s'agiter et à effectuer des rapprochements gênants. Pensons, enfin, à l'excommunication des «Sentinellistes » franco-américains du Rhode-Island, qui avaient osé traîner leur évêque (irlandais) devant les tribunaux civils pour contester ses visées assimilatrices. Le message de la hiérarchie était clair : catholicisme et nationalisme ne faisaient pas bon ménage...

$\mathrm{Au}$ Québec, les interventions pontificales eurent pour effet d'écarteler les nationalistes « orthodoxes » (ou « groulxistes ») entre une droite nationaliste qui accordait de moins en moins d'importance au salut des âmes et une gauche catholique qui concevrait l'apostolat chrétien en termes strictement religieux et sociaux et en marge de toute considération nationale ou politique $^{155}$. En Ontario français, les conséquences des prises de position romaines ne furent pas moins négligeables. À la fin de la crise du Règlement 17, plusieurs des militants les plus nationalistes de la première heure, dont le père Charlebois, furent limogés ${ }^{156}$. Le mot d'ordre, désormais, était prudence. Dans le Nouvel-Ontario, on avait pris bonne note, là aussi, de l'hostilité croissante du Saint-Siège envers toute forme de nationalisme. M ${ }^{\text {gr }}$ Joseph Hallé, vicaire apostolique de l'Ontario-Nord et ancien représentant du

155. Yvan Lamonde, La Modernité au Québec. Tome $1:$ La crise de l'homme et de l'esprit, 1929-1939, Montréal, Fides, 2011, 323 p. ; Michel Bock, « Le Rapport au politique dans le nationalisme groulxiste : entre méfiance et tentation », article inédit.

156. Voir Robert Choquette, La Langue gardienne de la foi en Ontario, op. cit., p. $210-213,219-222$. 
clergé canadien-français à Rome, conseilla à l'AcFÉo de ne pas « faire du nationalisme ${ }^{157}$ » afin de conserver le crédit qu'elle avait encore au sein de la hiérarchie. Lors des tractations entourant la succession de Scollard en 1934, autre exemple, le docteur Hurtubise reconnut que « son plus grand souci » avait été de « ménager les susceptibilités du délégué [apostolique] à propos de "racisme" ou de "nationalisme outrancier" [...]" ${ }^{158} »$, faisant ici référence à la condamnation de L'Action française de Charles Maurras. Pendant les premières années de la crise scolaire, on ne se s'était pas gêné pour conspuer les « ennemis » et les « persécuteurs » du peuple canadien-français en Ontario, ni pour prêcher la désobéissance civile en revendiquant le rétablissement de ses droits scolaires. À partir des années 1920, toutefois, de telles stratégies n'étaient plus guère envisageables. Le cas du diocèse de Sault-Sainte-Marie illustre à merveille la transformation du climat intellectuel franco-ontarien, dont la modération contrasterait singulièrement, dès lors, avec la fougue et l'irrévérence qu'il n'avait pas été rare de constater auparavant. Désormais, l'élite franco-ontarienne préférerait agir dans la discrétion. En 1926, la fondation, à Ottawa, de l'Ordre de Jacques-Cartier, dans lequel les nationalistes catholiques non repentis s'étaient réfugiés, n'était pas le fruit du hasard. Pendant les quarante prochaines années, le développement de l'Ontario français se ferait, pour une bonne part, dans les coulisses, loin des feux de la rampe...

157. « Notes de $\mathrm{M}^{\mathrm{gr}}$ Hallé », [après 1923], CrCCF, FACFO, C2/153/7.

158. Lettre de J.-Raoul Hurtubise aux Commandeurs de l'Ordre de JacquesCartier, 18 octobre 1934, citée dans Robert Choquette, La Langue gardienne de la foi en Ontario, op. cit., p. 64. 